\title{
The Instability of Matching with Overconfident Agents
}

\author{
Siqi Pan*
}

July 28,2018

\begin{abstract}
Many centralized college admissions markets allocate seats to students based on their performance on a single standardized exam. The exam's measurement error can cause the exam-derived priorities to deviate from colleges' aptitude-based preferences. Previous literature proposes to combine pre-exam preference submission with a Boston algorithm (a PreExam-BOS mechanism). This paper examines the proposed mechanism in an experiment where students are not fully informed of their relative aptitudes. The results show pre-exam preference submission is distorted by overconfidence and PreExam-BOS fails to achieve stable matching with respect to aptitudes. Compared to a post-score Serial Dictatorship mechanism, which is robust to overconfidence but more prone to the exam's measurement error, PreExam-BOS creates more mismatches and a greater variance in the extent of mismatches: some students receive a large advantage while others are hurt considerably. Moreover, PreExam-BOS rewards overconfidence and punishes underconfidence. The observed overconfidence cannot be mitigated with an improved information condition.
\end{abstract}

Keywords: school choice matching, college admission, overconfidence, gender

JEL: C78, C92, I28, D91, J16

\section{Introduction}

In admissions, colleges usually prefer students with certain qualities or aptitudes that are not readily observable. Students are therefore evaluated by noisy signals such as SAT scores and

*Department of Economics, The University of Melbourne, VIC 3010, Australia (e-mail: siqi.pan@unimelb.edu.au). I am deeply indebted to my advisor Paul J. Healy for countless conversations and encouragement while advising me on this project. I would like to thank John Kagel, Lucas Coffman, Katie Baldiga Coffman, Huanxing Yang, Yaron Azrieli, Hal Arkes, Clayton Featherstone, Yan Chen, John Hatfield, SangMok Lee, Marek Pycia, Alex Gotthard-Real, Ritesh Jain, Anthony Bradfield, seminar participants at the Ohio State University, and audiences at the 2015 North American Economic Science Association Conference and the 2017 SAET Conference on Current Trends in Economics for helpful comments and inspiration. I am grateful to Ming Jiang, Hengli Zhang, Ming Pan, and Qiquan Xu for their help in the data collection process. This project was supported by JMCB Grants for Graduate Student Research in Economics. All remaining errors are mine. 
high-school transcripts. Some countries - including China, South Korea, Turkey, Russia, and Greece - simply use a standardized exam as an evaluation system, which means that every year around the world, more than 13 million students' college admissions are determined by their performance on a single exam. ${ }^{1}$

Since the exam is conducted only once a year, it greatly simplifies the admissions process and is thus especially favorable for large markets. However, a single exam always entails measurement error, and a student who underperforms on the exam may lose his or her placement at a preferred college to someone with a lower aptitude. Previous literature (discussed in more detail below) proposes a hopeful hypothesis that such an error in the evaluation system could be corrected with proper market design. Under the proposed mechanism, students apply to colleges or submit their preferences before taking the exam. If we assume that students have the knowledge of their relative aptitudes, this mechanism triggers a self-sorting process, with students who have higher (lower) aptitudes targeting more (less) preferred colleges. However, given the considerable evidence regarding self-evaluation biases such as overconfidence, I argue that in practice, students may not be able to sort themselves perfectly. In this case, the proposed solution may introduce a behavioral error into the admissions procedure. And the market outcome depends on the empirical realization of the newly introduced behavioral error and the existing measurement error from the exam. This paper presents a tradeoff between these two errors that may emerge in real markets in the presence of overconfident agents.

Formally, the above issue can be described as a college admissions problem, which is a matching problem that involves pairing members of one group of agents (students) with members of another group of agents (colleges). A centralized procedure, called a matching mechanism, is adopted to solve the problem based on students' submitted preferences for colleges along with their priority ordering at each college. The priority ordering, which is solely determined by the score ranking on a single standardized exam, serves as a noisy proxy for colleges' true preferences regarding students.

Suppose that all colleges prefer students with higher aptitudes and that students have correlated preferences for colleges. Then a matching mechanism is considered to have the socially desirable property of "fairness" if it matches more preferred colleges with students who have higher aptitudes, not just with those who have higher realized scores. To capture the notion of such fairness, a market outcome is said to be stable with regard to aptitude ("aptitude-stable") if it eliminates all cases in which a student with a higher aptitude is not assigned to a preferred college but instead another student with a lower aptitude is assigned to that college. ${ }^{2}$ In addition to fairness-related concerns, distortions from aptitude-stability can

\footnotetext{
${ }^{1}$ Table 7 in Appendix $\mathrm{C}$ provides the statistics for each representative country.

${ }^{2} \mathrm{~A}$ formal definition that considers the college's unoccupied seats is given in Section 2.1. Aptitude-stability, defined according to the true preferences of the market participants, is simply called "stability" in the standard matching literature (Gale and Shapley, 1962). Here I emphasize the word "aptitude" because in the current setting, we can also define stability according to the exam-based priorities, which may deviate from colleges'
} 
also lead to overall welfare loss from one of the consequences of unstable matching, namely, a costly re-matching process. In college admissions, this usually takes the form of students repeating their last year of high school and re-entering the market a year later.

Previous studies such as Jiang (2014), Lien, Zheng, and Zhong (2015, 2017), and Wu and Zhong (2014) propose a hopeful hypothesis that aptitude-stability is more likely to be achieved by a "pre-exam Boston mechanism" (henceforth "PreExam-BOS"), which combines a Boston matching algorithm with pre-exam preference submissions - that is, students are asked to submit their preferences before taking the exam. ${ }^{3}$ The argument goes as follows. A Boston algorithm is not strategy-proof; instead of truthful revelation, a student should indicate his or her first choice with a "safer" college at which the student is more likely to win a seat. With pre-exam preference submissions, students should employ a self-sorting strategy based on their ex-ante expected exam performance, which reflects their aptitudes. Then the seats at more desirable colleges will be "reserved" for students with higher aptitudes, since students with lower aptitudes will sort themselves into lower-ranked colleges.

The preceding argument hinges on the assumption that students are able to correctly sort themselves before taking the exam, which requires that each student's knowledge of the relative standing of his or her aptitude among all students is accurate enough. Such knowledge is then "reported" to the market designer through the way each student misrepresents his or her preferences under PreExam-BOS. However, considerable evidence has established the existence and heterogeneity of biases, such as overconfidence, in self-evaluation. In other words, while the proposed solution theoretically diminishes the effect of the measurement error of a single exam, it might introduce a behavioral error due to self-evaluation biases. As I show in this paper, these biases have important consequences for aptitude-stability.

Using a college admissions model, I first offer theoretical predictions regarding the market outcome under different matching mechanisms. Following previous literature, I mainly compare PreExam-BOS to a "post-score Serial Dictatorship mechanism" (henceforth "PostScoreSD"), which combines a Serial Dictatorship algorithm with post-score preference submission - that is, students submit their preferences after seeing the exam results. ${ }^{4}$ In contrast to PreExam-BOS, PostScore-SD is strategy-proof. With every student truthfully revealing his or her preferences, the matching outcome under PostScore-SD only depends on exam-based priorities and is thus distorted from aptitude-stability by the exam's measurement error. On the other hand, as a dominant strategy under PostScore-SD, truth-telling is not affected by a student's self-evaluation biases. Hence, compared to PreExam-BOS, PostScore-SD is more vulnerable to the noise from the single-exam system but less influenced by students' overor underconfidence. Which mechanism will create smaller distortions from aptitude-stability

aptitude-based preferences due to the measurement error of a single exam (see Section 2.1 for more details).

${ }^{3}$ The procedure of a Boston algorithm is described in Section 2.2.1.

${ }^{4}$ The procedure of a Serial Dictatorship algorithm is described in Section 2.2.2. 
depends on the relative magnitudes of these two effects. I also discuss a third timing of preference submission named "halfway," under which students submit preferences after the exam but before the revelation of exam results. Such a design is mainly inspired by real-world applications. According to Chen and Kesten (2017), the halfway timing was adopted by three provinces of China in their college admissions. Thus, a total of six mechanisms are considered: two algorithms (BOS and SD) combined with three timings of preference submission (pre-exam, halfway, and post-score). As I will elaborate in Section 2.4, under the framework of the current paper, the theoretical predictions of the halfway timing are very similar to those of the pre-exam timing.

Since we cannot exogenously vary the choice of mechanisms in the field, I conduct a laboratory experiment to investigate students' strategic behaviors and the market outcomes under different mechanisms. In an experimental market, each subject, playing the role of a student, is asked to take an exam, guess the exam results, and submit his or her preferences regarding simulated colleges to a matching algorithm. The exam is designed as a real-effort task in the laboratory, and a subject's aptitude is evaluated as his or her average performance on multiple exams. As treatments, different matching algorithms and timings of preference submission are adopted.

The experimental data confirm that a majority of students report their preferences truthfully under PostScore-SD, while under PreExam-BOS, their strategies are significantly distorted by over- or underconfidence. Thus, neither mechanism fully achieves aptitude-stability on the market level. To measure how much a student's welfare is distorted from an aptitudestable matching, I compare the desirability of the student's aptitude-stably matched college to that of his or her assignment under each treatment. The result shows that PreExamBOS creates more severe, noisier distortions from aptitude-stability than PostScore-SD. This is because not only are fewer students assigned to their aptitude-stably matched colleges, but the magnitudes of such welfare distortions are also more spread out among students. In other words, under PreExam-BOS, some students receive a large advantage while some others are considerably hurt, and neither the gains nor the losses can be justified by the students' aptitudes.

These results can be explained by three observations: (i) on average, students exhibit overconfidence; (ii) there is significant heterogeneity in their levels of overconfidence; (iii) students make more heterogeneous strategic choices under PreExam-BOS, as opposed to the highly aligned truth-telling behavior under PostScore-SD. In particular, under PreExam-BOS, subjects tend to choose more aggressive or optimistic strategies than self-sorting based on their guessed exam performances. Thus, in the setting of this study, PreExam-BOS introduces more noise into the admissions procedure through both self-evaluation biases and strategic behaviors. Regarding the welfare effect of overconfidence, I find that PreExam-BOS tends to reward those who are overconfident and punish those who are underconfident. Since the 
experimental data show that women exhibit less overconfidence than men, PreExam-BOS serves on average as a gender penalty for women in the current laboratory sample.

On the other hand, previous experimental studies that do not take overconfidence into account find evidence that PreExam-BOS can outperform PostScore-SD in terms of aptitudestability. ${ }^{5}$ The key difference lies in how subjects obtain information regarding their aptitudes before the exam. Lien et al. (2015) and Jiang (2014) focus mainly on experimental designs in which the exam component is not part of the subjects' choice problem. Instead, each student is directly provided with his or her score distribution (that is, the distribution from which the student's score will be drawn) together with the score distributions of all the other students in the market. One exception is the "Quiz" treatment in Lien et al. (2015), in which subjects are asked to take a short quiz; subjects' relative performance on the quiz determines which role they will play in a group. However, the score distribution and the relative aptitude of each role are predetermined and are directly provided to the subjects. In contrast, the design in the present paper comes closer to many field settings: subjects collect information from feedback provided by multiple practice exams, or "mock tests." As a result, overconfidence severely distorts pre-exam preference submission and prevents PreExam-BOS from achieving aptitude-stability.

In an attempt to minimize self-evaluation biases under the setting for this study, I introduce additional treatments in which I help subjects collect information by showing them all of the previous scores for every student in the market as well as all of their average scores. However, in these cases as well, the subjects' overconfidence remains at the same level, and PreExam-BOS continues to be inferior to PostScore-SD. Such a result indicates that subjects' overconfidence is mainly driven by their overoptimistic beliefs about how much they can improve on the upcoming exam. In other words, the observed biases mainly stem from a source that cannot easily be muted with an increased amount of information.

\subsection{Related Literature}

This study contributes to the recent literature on school choice and college admissions problems with a single-exam evaluation system. Lien et al. (2017), Jiang (2014), and Wu and Zhong (2014) theoretically compare PreExam-BOS and PostScore-SD and show that PreExam-BOS can outperform PostScore-SD in terms of aptitude-stability. Specifically, Lien et al. (2017) identify the conditions under which PreExam-BOS can or cannot achieve complete aptitude-stability. However, as previously mentioned, these studies assume that before taking the exam, students' knowledge of their relative aptitudes is accurate enough. Such

\footnotetext{
${ }^{5}$ In Lien et al. (2015), the advantage of PreExam-BOS in terms of aptitude-stability mainly appears in an additional 10-round learning treatment. Such an advantage is not significant in the original treatment due to subjects' deviation from equilibrium strategies, which is consistent with the aggressive strategic choices observed in the present paper.
} 
information is directly provided to subjects in the laboratory experiments conducted by Lien et al. (2015) and Jiang (2014), in which they find support for the above theoretical results. In contrast, the present paper relaxes this assumption by allowing biases in self-evaluation. Wu and Zhong (2014) conduct empirical research using data from a top university in China. They show that students admitted under PreExam-BOS exhibit similar or better college academic performance than those admitted through other mechanisms. This result provides some evidence that PreExam-BOS can match the top college with students who have higher aptitudes, yet it is silent about middle- or lower-ranked colleges as well as the overall matching outcome.

The present paper also contributes to the literature addressing the merits and flaws of the Boston algorithm compared to Serial Dictatorship and other strategy-proof algorithms including Deferred Acceptance and Top Trading Cycles. In a standard setting without uncertainty or imperfect information, the Boston algorithm is often considered inferior in terms of stability and efficiency (Abdulkadiroğlu and Sönmez, 2003; and Ergin and Sönmez, 2006). ${ }^{6}$ Such predictions were supported by one of the earliest laboratory experiments on school choice matching conducted by Chen and Sönmez (2006). On the other hand, the manipulability of the Boston algorithm can sometimes improve ex-ante efficiency because it reflects some information that is otherwise unobservable to a market designer (see, for example, Abdulkadiroğlu, Che, and Yasuda, 2011 and Featherstone and Niederle, 2016). Chen and Kesten (2017) expand the discussion by constructing a family of application-rejection mechanisms, with the Boston and Deferred Acceptance mechanisms being special cases.

Finally, the present paper is related to the literature on overconfidence across economics, psychology, and finance. Moore and Healy (2008) provide a detailed overview of different ways in which the literature has defined overconfidence, i.e., as overestimation, overplacement, or overprecision. They then offer a theory that reconciles these concepts and explains several inconsistencies that can be found in the existing evidence. As in the present study, other studies have used overconfidence to explain market failures in various environments, such as excessive business entry and trading volume, corporate investment distortions, and stock market bubbles, to name just a few (see Camerer and Lovallo, 1999; Glaser and Weber, 2007; Malmendier and Tate, 2005; and Odean, 1999). Moreover, it is well established that people exhibit heterogeneous levels of over- or underconfidence, which can be predicted by certain factors, including personality, gender, and cognitive abilities (see Barber and Odean, 2001; Coffman, 2014; Kleitman and Stankov, 2007; Niederle and Vesterlund, 2007; Schaefer, Williams, Goodie, and Campbell, 2004; and Stankov and Crawford, 1996). The present study has also found similar evidence in the laboratory.

The rest of this paper is organized as follows. In Section 2, I lay out the college admissions model and make theoretical predictions. Section 3 describes the laboratory experiment and presents experimental results. Section 4 concludes the paper.

\footnotetext{
${ }^{6}$ See also Klijn, Pais, and Vorsatz (2013) and Pais and Pintér (2008).
} 


\section{The Model}

\subsection{A College Admissions Problem}

The centralized matching market considered here is a variation of the college admissions problem (Gale and Shapley, 1962): there are a number of students; eac of them is to be assigned a seat at one of a number of colleges. Each student has strict preferences over all colleges and each college has strict preferences over all students. There is a maximum capacity at each college, but the total number of seats exceeds the total number of students. The distinguishing feature of this environment is that every college has a priority ordering of all students, which is not necessarily in accord with its preference relation over students: the former is determined by students' performance on a single exam, while the latter is determined by their intrinsic aptitudes. Formally, the college admissions problem consists of:

1. A set of students $I=\left\{i_{1}, \ldots, i_{n}\right\}, n \geq 2$.

2. A set of colleges $C=\left\{c_{1}, \ldots, c_{m}\right\}, m \geq 2$.

3. A capacity vector $q=\left(q_{c_{1}}, \ldots, q_{c_{m}}\right)$.

4. A list of strict student preferences $P_{I}=\left(P_{i_{1}}, \ldots, P_{i_{n}}\right)$. The preference relation $P_{i}$ of student $i$ is a linear order over $C \cup\{i\}$, where $c P_{i} c^{\prime}$ means that student $i$ strictly prefers college $c$ to college $c^{\prime}$ and $i$ denotes remaining unmatched. Students prefer any college to remaining unmatched.

5. A vector of students' aptitudes $a=\left(a_{1}, \ldots, a_{n}\right)$ and a corresponding vector of aptitude ranks $r_{a}=\left(r_{a_{1}}, \ldots, r_{a_{n}}\right)$, where $a_{i}$ denotes student $i$ 's aptitude and $r_{a_{i}}$ denotes the rank of student $i$ 's aptitude among all students (with 1 being the highest rank). Ties in aptitudes are randomly broken.

6. A vector of students' exam scores $s=\left(s_{1}, \ldots, s_{n}\right)$ and a corresponding vector of exam score ranks $r_{s}=\left(r_{s_{1}}, \ldots, r_{s_{n}}\right)$, where $s_{i}$ denotes student $i$ 's exam score and $r_{s_{i}}$ denotes the rank of student $i$ 's exam score among all students (with 1 being the highest rank). Ties in scores are randomly broken.

7. A list of strict college preferences $P_{C}=\left(P_{c_{1}}, \ldots, P_{c_{m}}\right)$. The preference relation $P_{c}$ of college $c$ is a linear order over $I \cup\{c\}$, where $i P_{c} i^{\prime}$ means that college $c$ strictly prefers student $i$ to student $i^{\prime}$ and $c$ denotes leaving a seat empty. Colleges prefer any student to leaving a seat empty. Colleges have identical preferences over students, which are determined by students' aptitude ranking; i.e., $i P_{c} i^{\prime} \Leftrightarrow r_{a_{i}}<r_{a_{i^{\prime}}}, \forall c \in C$. 
8. A strict priority ordering of students at every college that is determined by students' exam score ranking: student $i$ has a higher priority than student $i^{\prime}$ at every college if and only if $r_{s_{i}}<r_{s_{i^{\prime}}}$. All colleges have the same priority ordering.

Student $i$ 's exam score is given by $s_{i}=a_{i}+\xi_{i}$, where $\xi_{i}$ is the measurement error of an exam. I assume that a student's aptitude is the mean and the mode of his or her exam score distribution; that is, one exam score is an unbiased but noisy measure of aptitude.

Assumption 1. For student $i$, an exam's measurement error $\xi_{i}$ follows a distribution on the real line with mean 0 and non-zero standard deviation. ${ }^{7}$

Similarly, student $i$ 's exam score rank is given by $r_{s_{i}}=r_{a_{i}}-\epsilon_{i}$, where $\epsilon_{i}$ is the measurement error of the exam in terms of rank. ${ }^{8}$

Below I make a simplifying assumption following previous literature.

Assumption 2. Students have identical preferences over colleges. ${ }^{9}$

Without loss of generality, assume in addition that a college with a smaller index is more desirable; i.e., $c_{j} P_{i} c_{j^{\prime}} \Leftrightarrow j<j^{\prime}, \forall i \in I$.

The outcome of a matching market is known as a matching. Formally, a matching is a function $\mu: I \cup C \rightarrow 2^{I} \cup C$ such that for any $i \in I$ and any $c \in C$, (i) $\mu(i) \in C \cup i$, (ii) $\mu(c) \in 2^{I}$, (iii) $\mu(i)=c$ if and only if $i \in \mu(c)$, and (iv) $|\mu(c)| \leq q_{c}$. Thus, $\mu(i)$ denotes the assignment of student $i$ under matching $\mu$, and $\mu(c)$ denotes the set of students who are matched to college $c$ under matching $\mu$.

In the matching literature, stability is used as a central criterion to evaluate a matching outcome. Under the current structure, we can either set such a criterion according to colleges' aptitude-based preferences, or according to their exam-based priorities. They are called stability with regard to aptitude and stability with regard to exam score, respectively. ${ }^{10}$ The definitions are given below.

Definition 1. A matching $\mu$ is stable with regard to aptitude ("aptitude-stable") if and only if there is no student-college pair $(i, c)$ such that student $i$ prefers college $c$ to his or her assignment $\mu(i)$ and either (1) college $c$ has empty seats under $\mu$, or (2) at least one of the students in $\mu(c)$ has a lower aptitude than student $i$.

\footnotetext{
${ }^{7}$ The distribution of $\xi_{i}$ can be continuous or discrete. Assumption 1 is essentially an assumption on $s_{i}$ and $a_{i}$ because $\xi_{i}$ is derived from $\xi_{i}=s_{i}-a_{i}$. Empirically, it can be easily satisfied with normalization.

${ }^{8}$ Here I use $\epsilon_{i}=r_{a_{i}}-r_{s_{i}}$ instead of $\epsilon_{i}=r_{s_{i}}-r_{a_{i}}$ to be consistent with the definition of overplacement in Section 2.3.

${ }^{9}$ It reflects the reality of many college admissions markets that students' preferences over colleges are correlated. Following previous literature, here I simplify the environment by assuming homogeneity. Although relaxing such an assumption is a well-motivated extension, it is not the focus of the present paper.

${ }^{10}$ Similar concepts are named ex-post and ex-ante fairness in a school choice setting.
} 
Definition 2. A matching $\mu$ is stable with regard to exam score ("score-stable") if and only if there is no student-college pair $(i, c)$ such that student $i$ prefers college $c$ to his or her assignment $\mu(i)$ and either (1) college $c$ has empty seats under $\mu$, or (2) at least one of the students in $\mu(c)$ has a lower exam score than student $i$.

Clearly, aptitude-stability is more socially desirable than score-stability since it respects colleges' true preferences, which are assumed to be based on students' aptitudes instead of their scores in one exam. Below I use a simple example to illustrate the environment.

Example 1. Suppose there are three students $I=\left\{i_{1}, i_{2}, i_{3}\right\}$ and three colleges $C=\left\{c_{1}, c_{2}, c_{3}\right\}$ in the market. Each college has only one slot to fill $q=\{1,1,1\}$. Students have homogeneous preferences over colleges: $c_{1} P_{i} c_{2}$ and $c_{2} P_{i} c_{3}, i=1,2,3$. On a single exam, students' performance is consistent with their aptitudes with probability 0.5 ; they overperform with probability 0.25 , and underperform with probability 0.25 . Table 1 shows the score distributions, which are independent across students.

Table 1: Score Distributions and Aptitudes (Example 1)

\begin{tabular}{c|c|c|ccc}
\hline Student & Aptitude & $\begin{array}{c}\text { Score } \\
\text { (Prob.) }\end{array}$ & $\begin{array}{c}\text { Overperform } \\
(0.25)\end{array}$ & $\begin{array}{c}\text { Consistent } \\
(0.50)\end{array}$ & $\begin{array}{c}\text { Underperform } \\
(0.25)\end{array}$ \\
\hline$i_{1}$ & $a_{1}=12$ & $s_{1}=$ & 16 & 12 & 8 \\
$i_{2}$ & $a_{2}=15$ & $s_{2}=$ & 19 & 15 & 11 \\
$i_{3}$ & $a_{3}=9$ & $s_{3}=$ & 13 & 9 & 5 \\
\hline
\end{tabular}

A student's aptitude is given by the mean and mode of his or her score distribution. The second column of Table 1 implies students' aptitude ranks $r_{a}=(2,1,3)$, which determine every college's aptitude-based preferences. So the unique aptitude-stable matching is

$$
\begin{array}{lll}
i_{1} & i_{2} & i_{3} \\
c_{2} & c_{1} & c_{3}
\end{array}
$$

However, students may exhibit any ranking in their exam scores. ${ }^{11}$ With probability $\frac{17}{64}$, the exam's measurement error leads to the realized score ranks $r_{s}=(1,2,3)$. In this case, the unique score-stable matching is

$$
\begin{array}{lll}
i_{1} & i_{2} & i_{3} \\
c_{1} & c_{2} & c_{3}
\end{array},
$$

which is not aptitude-stable because both $i_{2}$ and $c_{1}$ prefer each other to their current assignments.

\footnotetext{
${ }^{11}$ Table 8 in Appendix $\mathrm{C}$ shows the probability of every possible score ranking.
} 
Example 1 shows how an exam's measurement error could distort students' realized score ranking from their aptitude ranking and thus prevent the score-stable matching from achieving aptitude-stability. Below I compare different mechanisms (combinations of a matching algorithm and a timing of preference submission) and examine which one is less likely to be effected by such noise from a single exam and is more likely to yield an aptitude-stable matching.

\subsection{Two Matching Algorithms}

To select a matching for the college admissions problem defined above, a systematic procedure, called a "matching algorithm," allocates students to colleges depending on students' submitted preferences and colleges' priority ordering. In terms of timing, preference submission could occur before or after the exam, but the actual matching algorithm is always conducted after preference submission and the revelation of exam results.

In the literature of college admissions and school choice problems, three matching algorithms are most widely discussed: the Boston algorithm (BOS), the Gale-Shapley Deferred Acceptance algorithm (DA), and the Top Trading Cycles algorithm (TTC). In the current setting where all colleges share the same priority ordering, TTC reduces to a Serial Dictatorship algorithm (SD) and is equivalent to DA (Kesten, 2006). Therefore, BOS and SD are the two competing algorithms considered in the present paper.

\subsubsection{The Boston Algorithm (BOS)}

Each student submits his or her preferences by ranking all colleges. Every college has the same strict priority ordering of students, which is determined by students' exam score ranking.

Step 1: Only the 1st choices of all students are considered. For each college, consider the students who have listed it as their 1st choice; assign seats of the college to these students one at a time following their priority ordering until either there are no seats left or there are no students left who have listed it as their 1st choice.

In general, Step $k(k \geq 1)$ can be described as follows.

Step $k$ : Only the $k$ th choices of the remaining students (who have not been assigned a seat previously) are considered. For each college with still available seats, consider the students who have listed it as their $k$ th choice; assign the remaining seats to these students one at a time following their priority ordering until either there are no seats left or there are no students left who have listed it as their $k$ th choice.

The procedure terminates after any step $k$ when every student is assigned a seat at some college, or if the only students who remain unassigned listed no more than $k$ choices. 


\subsubsection{The Serial Dictatorship Algorithm (SD)}

Each student submits his or her preferences by ranking all colleges. Every college has the same strict priority ordering of students, which is determined by students' exam score ranking.

Step 1: The student with the highest priority is considered. She is assigned a seat at the college of her 1st choice.

Step 2: The student with the second highest priority is considered. He is assigned a seat at his 1st choice if that college still has empty seats left; otherwise, he is assigned a seat at his 2 nd choice.

In general, Step $k(k \geq 2)$ can be described as follows.

Step $k$ : The student with the $k$ th highest priority is considered. She is assigned a seat at her most preferred college that has an empty seat.

The procedure terminates when every student has been considered, or when no college seats remain.

\subsection{Three Timings of Preference Submission}

Apart from matching algorithms, the timing of preference submission can also largely affect the strategic behaviors of market participants, thus influencing the market outcome. Inspired by college admissions in China, I focus on three different timings, under which students are asked to submit their preferences at different stages, or different information statuses. The timings and stages are named as follows.

The "ex-ante," "interim," and "ex-post" stages refer to: before the exam, after the exam but before the revelation of exam results, and after the revelation of exam results. ${ }^{12}$ Under the timings named "pre-exam," "halfway," and "post-score," students submit their preferences at the ex-ante, interim, and ex-post stages, respectively. The following assumption specifies the information status at the ex-post stage.

Assumption 3. At the ex-post stage (after the revelation of exam results), it is common knowledge that every student knows his or her own exam score rank.

When submitting preferences under the pre-exam and halfway timings, students do not observe the exam results, which means they do not know their priority ordering at each college. In some situations (discussed in Section 2.4), their strategies may depend on their guessed exam results. Therefore, under the pre-exam timing, a component is added to the college admissions problem defined in Section 2.1:

\footnotetext{
${ }^{12}$ The interim stage is defined as a distinct information status, because a student may obtain additional information during the exam.
} 
9. A vector of students' guessed exam scores $\hat{s}^{E A}=\left(\hat{s}_{1}^{E A}, \ldots, \hat{s}_{n}^{E A}\right)$ and a corresponding vector of students' guessed exam score ranks $\hat{r}_{s}^{E A}=\left(\hat{r}_{s_{1}}^{E A}, \ldots, \hat{r}_{s_{n}}^{E A}\right)$ at the ex-ante stage, where $\hat{s}_{i}^{E A}$ and $\hat{r}_{s_{i}}^{E A}$ denote student $i$ 's guessed score and guessed rank.

Under the halfway timing, the following component is added instead:

9'. A vector of students' guessed exam scores $\hat{s}^{I N}=\left(\hat{s}_{1}^{I N}, \ldots, \hat{s}_{n}^{I N}\right)$ and a corresponding vector of students' guessed exam score ranks $\hat{r}_{s}^{I N}=\left(\hat{r}_{s_{1}}^{I N}, \ldots, \hat{r}_{s_{n}}^{I N}\right)$ at the interim stage, where $\hat{s}_{i}^{I N}$ and $\hat{r}_{s_{i}}^{I N}$ denote student $i$ 's guessed score and guessed rank.

In the current setting, overconfidence, defined as a bias in self-evaluation, can be measured in score or rank. Following Moore and Healy (2008), I refer to score overconfidence as "overestimation," and rank overconfidence as "overplacement."

Definition 3. Student $i$ 's overestimation at the ex-ante stage is given by $\delta_{i}^{E A} \equiv \hat{s}_{i}^{E A}-E\left[s_{i}\right]=$ $\hat{s}_{i}^{E A}-a_{i}$ and at the interim stage by $\delta_{i}^{I N} \equiv \hat{s}_{i}^{I N}-E\left[s_{i}\right]=\hat{s}_{i}^{I N}-a_{i}$.

Definition 4. Student $i$ 's overplacement at the ex-ante stage is given by $\theta_{i}^{E A} \equiv r_{a_{i}}-\hat{r}_{s_{i}}^{E A}$ and at the interim stage by $\theta_{i}^{I N} \equiv r_{a_{i}}-\hat{r}_{s_{i}}^{I N} \cdot{ }^{13}$

Naturally, a student is said to exhibit underconfidence when the above measures take negative values.

\subsection{Theoretical Predictions}

This section gives the theoretical predictions for strategies of market participants and the stability of matching outcomes under different combinations of matching algorithms and timings of preference submission. I refer to the SD (BOS) algorithm under pre-exam, halfway, or post-score timing as "PreExam-SD," "Halfway-SD," or "PostScore-SD" mechanism ("PreExamBOS," "Halfway-BOS," or "PostScore-BOS" mechanism). The results in Propositions 1 to 3 are largely borrowed from previous literature. The most closely related study is that of Lien et al. (2017), where similar conclusions are drawn under a slightly different setting (see a more detailed discussion below).

Proposition 1. (1) PreExam-SD, Halfway-SD, and PostScore-SD are strategy-proof. (2) PostScore-SD always yields the score-stable matching. (3) PreExam-SD and Halfway-SD yield the score-stable matching in the truth-telling equilibrium.

\footnotetext{
${ }^{13}$ First, note that overplacement is defined as $E\left[r_{s_{i}}\right]-\hat{r}_{s_{i}}^{E A}$ (or $E\left[r_{s_{i}}\right]-\hat{r}_{s_{i}}^{I N}$ ) instead of $\hat{r}_{s_{i}}^{E A}-E\left[r_{s_{i}}\right]($ or $\hat{r}_{s_{i}}^{I N}-E\left[r_{s_{i}}\right]$ ), because a smaller value of rank means being better in aptitude or exam score. Second, there is a slight abuse of terminology in the definitions of $\delta_{i}^{I N}$ and $\theta_{i}^{I N}$. At the interim stage, a student has obtained some additional information, say a signal $t$, about his or her performance on the exam. Therefore, strictly speaking, overestimation and overplacement should be measured as $\hat{s}_{i}^{I N}-E\left[s_{i} \mid t\right]$ and $E\left[r_{s_{i}} \mid t\right]-\hat{r}_{s_{i}}^{I N}$, respectively. The current definitions are adopted since it is more relevant in this environment to discuss how the aptitude ranking is distorted by students' guessed exam results. Third, because the measurement error of an exam has zero mean, overconfidence evaluated relative to posterior beliefs has the same average level as that evaluated relative to prior beliefs.
} 
It is well-established in the literature that SD is strategy-proof for any realized priority ordering over students, which means truth-telling is a weakly dominant strategy for every student, regardless of his or her knowledge about the priority ordering at the time of preference submission. Hence, no matter which timing of preference submission is adopted, SD always implements the score-stable matching outcome in the truth-telling equilibrium (see Appendix A for a more detailed proof).

In contrast, students have strong incentives to misrepresent their true preferences under BOS. The following definition specifies a strategy in preference submission at the ex-post stage.

Definition 5. A student $i$ is said to adopt a score-based sorting strategy if the student lists college $c_{j}$ as his or her first choice in preference submission such that $\sum_{k=1}^{j-1} q_{k}<r_{s_{i}} \leq$ $\sum_{k=1}^{j} q_{k}{ }^{14}$

In the current setting, score-based sorting means listing one's score-stably matched college as the first choice. Recall the environment in Example 1, where every college has only one seat, and students' realized score ranks are $r_{s}=(1,2,3)$. Then we say all students exhibit score-based sorting if the submitted first choices of $i_{1}, i_{2}$, and $i_{3}$ are given by $c_{1}, c_{2}$, and $c_{3}$. Hence, BOS will have every student accepted in Step 1 of the procedure and achieve scorestability. Below, Proposition 2 shows that score-based sorting is an equilibrium strategy under PostScore-BOS, and the score-stable matching is implemented in equilibrium (the formal proof is given in Appendix A).

Proposition 2. (1) Under PostScore-BOS, there is a Nash equilibrium where every student exhibits score-based sorting. (2) PostScore-BOS always implements the score-stable matching.

Under PreExam- and Halfway-BOS, students do not observe their exam score ranks at the time of preference submission; their strategies are thus affected by their guessed exam results at the ex-ante and interim stages, respectively. As a counterpart of score-based sorting, guessbased sorting is defined below.

Definition 6. Under the pre-exam (or halfway) timing, a student $i$ is said to adopt a guessbased sorting strategy if the student lists college $c_{j}$ as his or her first choice in preference submission such that $\sum_{k=1}^{j-1} q_{k}<\hat{r}_{s_{i}}^{E A} \leq \sum_{k=1}^{j} q_{k}\left(\right.$ or $\sum_{k=1}^{j-1} q_{k}<\hat{r}_{s_{i}}^{I N} \leq \sum_{k=1}^{j} q_{k}$ ).

For PreExam- or Halfway-BOS to implement an aptitude-stable matching, it is important that every student's guessed rank is an accurate enough reflection of his or her aptitude rank, which should be commonly known to the market. Therefore, previous literature makes the following assumption and gives the prediction stated in Proposition 3.

\footnotetext{
${ }^{14}$ The concept is also named rank bias in the literature.
} 
Assumption 4. It is common knowledge that no student exhibits any over-or underplacement.

Proposition 3. If Assumption 4 (common knowledge of no over-or underplacement) holds for preference submission at the ex-ante stage (or at the interim stage) and every student exhibits guess-based sorting, PreExam-BOS (or Halfway-BOS) yields the aptitude-stable matching.

The proof of the above proposition is straightforward. Under Assumption 4, every student who exhibits guess-based sorting lists his or her aptitude-stably matched college as the first choice. ${ }^{15}$ Under BOS, everyone is accepted in Step 1 and aptitude-stability is achieved.

However, if Assumption 4 fails, that is if students exhibit over- or underplacement, the conclusion in Proposition 3 will change significantly. Based on the fact that people are not aware of their own biases, and evidence on the false-consensus effect, I make the following assumption instead. ${ }^{16}$

Assumption $4^{\prime}$. Every student believes that he or she exhibits no over- or underplacement and that other students exhibit no over- or underplacement.

The beliefs specified in Assumption $4^{\prime}$ will be false in the presence of over- or underplacement. Since students' strategies under PreExam- and Halfway-BOS hinge on these beliefs, the matching outcome will be affected as well. This provides the intuition for Proposition 4 .

Proposition 4. If Assumption 4 is replaced by $4^{\prime}$ for preference submission at the ex-ante stage (or at the interim stage) and every student exhibits guess-based sorting, PreExam-BOS (or Halfway-BOS) may fail to achieve aptitude-stability.

On the other hand, truth-telling under PreExam-, Halfway-, and PostScore-SD and scorebased sorting under PostScore-BOS do not depend on students' guessed exam results. Therefore, the market outcomes under these four mechanisms are less easily affected by over- or underconfidence.

\subsubsection{Discussion of Propositions 3 and 4}

Due to the behavioral nature of this paper, the college admissions problem constructed in Section 2.1 does not constrain students' cardinal utilities, their risk attitudes, their self-evaluation biases, or the exam's measurement error. As a result, neither Proposition 3 nor Proposition 4

\footnotetext{
${ }^{15}$ An alternative condition is identified in Lien et al. (2017): except for the student with the lowest aptitude, every student exhibits guess-based sorting and is accepted by his or her first choice. Under Lien et al.'s framework, such a condition indicates that the student with the lowest aptitude is indifferent between all strategies.

${ }^{16}$ Under the false-consensus effect, people tend to believe that others are similar to them; see Ross, Greene, and House (1977) for a seminal contribution and Marks and Miller (1987) for a survey. Evidence on such an effect is also found in the laboratory experiment for this study (Section 3.3; Result 4).
} 
can give equilibrium predictions for a general environment. Rather, these serve as a guideline for the subsequent experimental analysis, in which both the conditions and the claims in these propositions are examined using subjects' strategic behaviors and market outcomes in the laboratory. In contrast, Lien et al. (2017) construct a more detailed model in their theoretical paper, where they specify the sufficient and necessary conditions under which PreExam-BOS implements the aptitude-stable matching in a pure-strategy Nash equilibrium.

Below I illustrate the predictions of Propositions 3 and 4 in the setting of Example 1.

Example 1 (Cont.) (i) Recall that students' aptitude ranks are $r_{a}=(2,1,3)$ and their exam score ranks are $r_{s}=(1,2,3)$. Suppose their guessed ranks at the ex-ante stage are given by $\hat{r}_{s}^{E A}=(1,1,2)$. Then both PreExam-and PostScore-SD yield the score-stable matching in the truth-telling equilibrium; under PostScore-BOS, if $i_{1}, i_{2}$, and $i_{3}$ all exhibit score-based sorting by submitting $c_{1}, c_{2}$, and $c_{3}$ as their first choices respectively, the score-stable matching is again implemented. However, under PreExam-BOS, if $i_{1}, i_{2}$, and $i_{3}$ all exhibit guess-based sorting by submitting $c_{1}, c_{1}$, and $c_{2}$ as their first choices, the following matching is implemented:

$\begin{array}{lll}i_{1} & i_{2} & i_{3} \\ c_{1} & c_{3} & c_{2}\end{array}$

(ii) Now suppose the exam's measurement error is given by $\epsilon=(0,0,0)$ and thus $r_{s}=r_{a}=$ $(2,1,3)$; all else stays the same. Then PreExam-BOS yields the following matching with everyone exhibiting guess-based sorting:

$$
\begin{array}{lll}
i_{1} & i_{2} & i_{3} \\
c_{3} & c_{1} & c_{2}
\end{array}
$$

Part (i) of the example indicates that under PreExam- and Halfway-BOS, overconfidence has two effects on the matching procedure. ${ }^{17}$ First, it directly distorts the sorting in preference submission: under the influence of overplacement, $i_{3}$ submits $c_{2}$ as the first choice, while $i_{1}$ submits $c_{1}$ and ends up competing with $i_{2}$ in Step 1 of BOS. Second, it brings back the noise from the exam's measurement error: due to the first effect, BOS needs to resolve the competition between $i_{1}$ and $i_{2}$ according to their exam scores and as a result of the exam's measurement error, $i_{1}$ is matched with $c_{1}$ although $i_{2}$ has a higher aptitude. Therefore, PreExam- and Halfway-BOS can be directly affected by the presence of self-evaluation biases and meanwhile, indirectly by the noise from a single-exam evaluation system.

As for individual welfare, under the setting of Part (i), $i_{2}$ is unbiased but is punished

\footnotetext{
${ }^{17}$ Given the definitions of overconfidence at the interim stage (see Definitions 3 and 4; Footnote 13), in this model the halfway timing is theoretically equivalent to the pre-exam timing. Therefore, Example 1 also has implications for Halfway-BOS and Halfway-SD.
} 
since $i_{2}$ is allocated to $c_{3}$ instead of his or her aptitude-stable match $c_{1}$, while both $i_{1}$ and $i_{3}$ are rewarded for being overconfident $\left(i_{1}\right.$ is matched to $c_{1}$ instead of $c_{2} ; i_{3}$ is matched to $c_{2}$ instead of $c_{3}$ ). On the other hand, from Part (ii) of the example, we can see the same level of overplacement hurts $i_{1}$ but benefits $i_{3}$.

Hence, regarding the effects of overconfidence on the market outcome and on individual welfare, the prediction from the model is ambiguous since it depends on the distribution of overconfidence and the realization of the exam's measurement error. To further explore these issues, I conduct a laboratory experiment in which subjects' preferences are induced by monetary incentives. Such a controlled setting allows me to closely observe their strategic choices, examine market stability, and analyze individual welfare.

\section{A Laboratory Experiment}

To investigate strategic behaviors and market outcomes under different mechanisms, I design an experiment with various combinations of matching algorithms and timings of preference submission. Compared to other experimental studies in the literature, the distinguishing feature of this design lies in how subjects obtain information regarding their aptitudes. Lien et al. (2015) and Jiang (2014) focus mainly on experimental designs in which the exam component is not part of the subjects' choice problem. Instead, each student is directly provided with his or her score distribution together with the score distributions of all the other students in the market. One exception is the "Quiz" treatment in Lien et al. (2015), in which subjects are asked to take a short quiz; subjects' relative performance on the quiz determines which role they will play in a group. However, the score distribution and the relative aptitude of each role are predetermined and are directly provided to the subjects. There is thus much less scope for over- or underconfidence since subjects are provided with perfect information of their aptitude ranking. In my design, the exam component is introduced as a real-effort task; subjects evaluate themselves at the ex-ante and interim stages using feedback provided by multiple practice exams, or "mock tests." Such a setting resembles many field environments and allows us to examine the existence of self-evaluation biases. In addition, to control for factors that can potentially affect subjects' strategic choices, at the end of the experiment I elicit their beliefs about other participants' overconfidence level as well as their risk attitudes.

\subsection{Experimental Design}

Each experimental market consists of five students and five colleges. Each subject plays the role of a student; colleges are simulated in the environment since they are not strategic. Colleges are labeled as $c_{1}, c_{2}, c_{3}, c_{4}$, and $c_{5}$; each has only one slot to fill. All students have the same induced preferences over colleges: when matched with $c_{1}, c_{2}, c_{3}, c_{4}$, or $c_{5}$, a student 
receives a payoff of $\$ 20, \$ 15, \$ 10, \$ 5$, or $\$ 0$, respectively.

Students' priority ordering at each college is determined by their score ranking in an exam. The exam consists of 20 IQ multiple choice questions, and students have 3 minutes to work. One's score equals the number of correct answers; there is no penalty for wrong answers. ${ }^{18}$ In order to obtain a strict score ranking and thus a strict priority ordering, ties are broken randomly. When exam results are revealed, each subject can observe the scores and ranks of all five students.

At the ex-ante stage (before the exam), students are asked to guess their exam scores and the rank of their scores in the market. Similarly, a guess of score and a guess of rank are again elicited at the interim stage (after the exam but before the revelation of exam results). These guesses are not observable to other students. ${ }^{19}$

Table 2: Treatment Design

\begin{tabular}{c||c|c}
\hline Timing & The BOS Algorithm & The SD Algorithm \\
\hline Pre-exam & PreExam-BOS & PreExam-SD \\
\hline Halfway & Halfway-BOS & Halfway-SD \\
\hline Post-score & PostScore-BOS & PostScore-SD \\
\hline
\end{tabular}

The experiment has a three-by-two treatment design (Table 2); varying the matching algorithm (BOS or SD) and the timing of preference submission (pre-exam, halfway, or postscore). Under the pre-exam timing, preference submission follows the guess at the ex-ante stage and precedes the exam; under the halfway timing, it follows the guess at the interim stage and precedes the revelation of exam results; and under the post-score timing, it comes after the revelation of results. At the end of every treatment, an algorithm is used to match students with colleges, based on students' submitted preferences and their exam score ranking.

Treatments using the same algorithm (in the same column of Table 2) are implemented within-subject. Every subject makes three sequences of decision making. As illustrated in Figure 1, all sequences include the same six components (an exam, a guess at the ex-ante stage, a guess at the interim stage, the revelation of exam results, preference submission, and a matching procedure), but differ in the timing of preference submission. To ensure a relatively clean treatment effect, the three timings appear in a random order, and no feedback is given in between regarding other students' submitted preferences or the final matching outcomes.

\footnotetext{
${ }^{18}$ Such a design aims to reduce the gender gap. Baldiga (2013) shows that when there is a penalty for wrong answers, women answer significantly fewer questions than men and thus do significantly worse conditional on their knowledge.

${ }^{19}$ Admittedly, the elicitation procedure may influence subjects' subsequent decisions. For example, subjects may be more likely to base their strategies in preference submission on the elicited beliefs. However, since the beliefs are elicited at both ex-ante and interim stages under all treatments, such an effect, if exists, should not interfere with any treatment effects.
} 


\section{Pre-exam:}

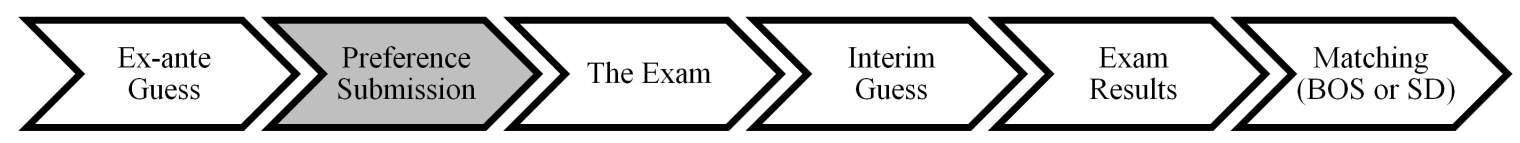

\section{Halfway:}

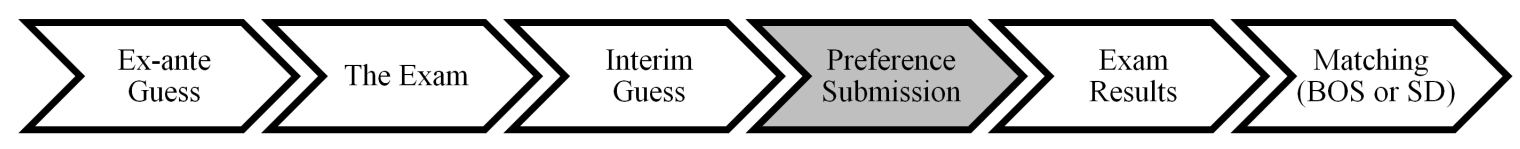

\section{Post-score:}

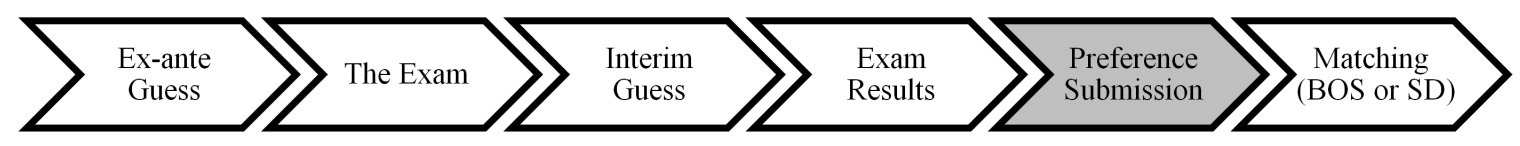

Figure 1: Timings of Preference Submission

Before the three treatments, subjects are given three "mock tests;" each takes the same form as the exam (20 questions over 3 minutes). The results, including the scores and ranks of all five students, are revealed at the end of every mock test. This process is for subjects to learn about their aptitudes, as well as the relative standing of their aptitudes, in taking the exam. Such a design provides three mock tests and three exams (one in each treatment) for every subject. I use the average of these six performances as the measure of aptitude. ${ }^{20}$

\subsection{Experimental Procedure}

Each session of the experiment consists of three parts. In the first part, either BOS or SD is described and illustrated with an example, followed by five practice rounds of preference submission with randomly assigned ranks (designed to familiarize subjects with the matching algorithm). The second part is the main experiment, three mock tests followed by three treatments. At the end of the second part but before giving any feedback on matching outcomes, I elicit beliefs about other participants' overconfidence level using a question like: "The computer will now randomly choose one of the other participants in the room. During the experiment, this participant has given a total of 6 guesses about his/her rank in the exam. Please give your guesses regarding the correctness of his/her responses by guessing the value of (his/her actual rank - his/her guessed rank) for each guess." The third part elicits risk attitudes using a variation of the lottery game from Holt and Laury (2002). ${ }^{21}$

\footnotetext{
${ }^{20}$ There is some evidence of learning during the three mock tests. The main results remain unchanged if I exclude all or some of the mock tests from the measure of aptitude.

${ }^{21}$ Subjects are asked to make 20 choices between paired lotteries; each pair consists of a "safe" option and a "risky" option. Following Holt and Laury (2002), the total number of safe choices (ranging from 0 to 20) is used as an indicator of risk aversion. A majority of subjects chose the safe option when the probability of the
} 
Subjects are randomly divided into groups of five and are re-grouped for every practice round of preference submission, every mock test, and every treatment. At the end of the experiment, one mock test, one guess (either a guess of one's own score or rank or a guess of another participant's overconfidence level), and the matching outcome in one treatment are randomly chosen for payment. A subject receives $\$ 0.25$ for each correct answer in the chosen mock test, plus $\$ 2$ if the chosen guess is correct, together with a payoff of $\$ 20, \$ 15$, $\$ 10, \$ 5$, or $\$ 0$, if the subject is matched with $c_{1}, c_{2}, c_{3}, c_{4}$, or $c_{5}$ in the chosen treatment. The final payment also includes the payoff from the lottery game, a show-up fee of $\$ 3$, and a \$1-payment for completing a questionnaire.

The experiment was conducted in February 2015 at the Experimental Economics Laboratory of The Ohio State University. There were seven sessions in total. One session had 10 subjects; one had 20; and the other five sessions were conducted with 15 subjects. Out of 95 subjects (41 females and 64 males), there were 60 participants for treatments using BOS, and 45 participants for treatments using SD. ${ }^{22}$ Each session lasted approximately 75 minutes. The average payment, including a show-up fee, was about $\$ 18.28$.

\subsection{Experimental Results}

Below I first evaluate the matching mechanisms by examining how frequently an aptitudestable outcome is produced under different treatments. The results in Section 3.3.1 show that compared to PostScore-SD, PreExam- and Halfway-BOS create an even more severe distortion from aptitude-stability, because a smaller proportion of students are allocated to their aptitude-stably matched colleges. Such market failures under PreExam- and HalfwayBOS could stem from students' self-evaluation biases or their deviations from the guessbased sorting strategy. Sections 3.3.2 and 3.3.3 analyze the aspects of belief and strategy, respectively. Section 3.3.4 investigates how students' individual welfare is affected by their beliefs and strategic choices under different mechanisms.

\subsubsection{Market Outcomes}

I start by examining the hypothesis on market outcomes according to the theoretical predictions in Propositions 1 to 3 . Result 1 shows how frequently an aptitude-stable or a score-stable outcome is produced on the market level. For more detail, I also analyze the proportion of aptitude-stably and score-stably matched student-college pairs (Result 2).

Hypothesis 1. (i) Score-stability is achieved under PreExam-SD, Halfway-SD, PostScore-

higher payoff was small, and then crossed over to the risky option without ever going back to the safe option. Only 7 out of 95 subjects exhibited back-and-forth behavior.

${ }^{22}$ For treatments using SD, the pilot data exhibit less variation since there exists a dominant strategy (truthtelling). Therefore, the power calculation prior to the experiment requires fewer data points. 
SD, and PostScore-BOS. (ii) Aptitude-stability is achieved under PreExam-BOS and Halfway$B O S$.

Result 1. (i) Score-stability is achieved in all markets under PostScore-SD, most markets under PreExam-SD, Halfway-SD, and PostScore-BOS, but no markets under PreExam-BOS or Halfway-BOS. (ii) Aptitude-stability is rarely achieved under any mechanism.

Figure 2 summarizes, for each treatment, the fraction of markets that yield the score-stable or aptitude-stable matching. ${ }^{23}$ As shown in Figure 2b, aptitude-stability is only observed in 2 out of 9 markets under Halfway-SD, and 1 out of 9 markets under PreExam- and PostScore$\mathrm{SD}$, which could be considered as coincidences because the aptitude-stable matching also happens to be score-stable in these four markets.

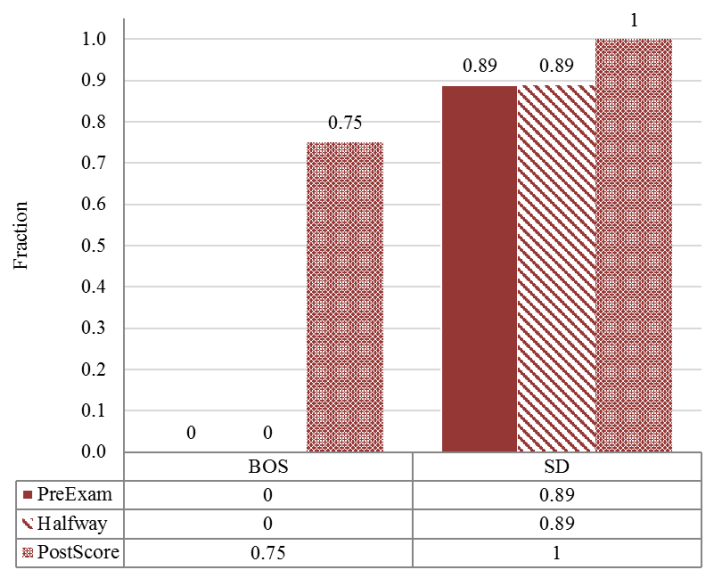

(a) Score-Stable Matchings

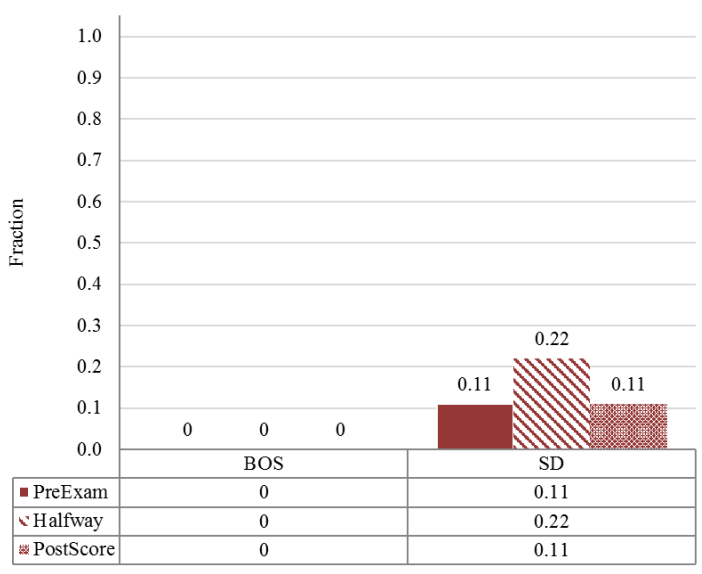

(b) Aptitude-Stable Matchings

Figure 2: Score-Stability and Aptitude-Stability

To measure how severely the market outcome is distorted from score-stability (aptitudestability) under each mechanism, I calculate the proportion of students who are allocated to their score-stably (aptitude-stably) matched colleges, that is, the proportion of score-stably (aptitude-stably) matched pairs.

Result 2. (i) PreExam-BOS and Halfway-BOS yield a smaller proportion of score-stably matched pairs than the other four mechanisms. (ii) PreExam-BOS and Halfway-BOS yield a smaller proportion of aptitude-stably matched pairs than Halfway-SD and PostScore-SD.

\footnotetext{
${ }^{23}$ There are a total of 12 markets under PreExam-, Halfway-, and PostScore-BOS, and a total of 9 markets under PreExam-, Halfway-, and PostScore-SD.
} 


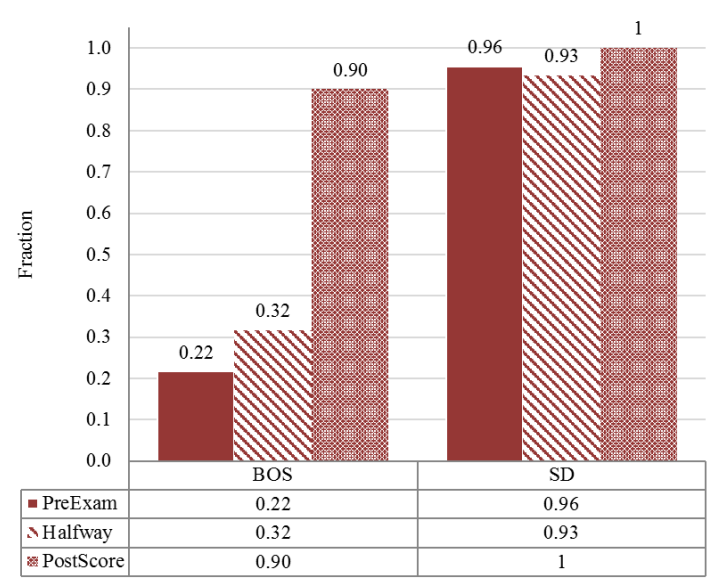

(a) Score-Stably Matched Pairs

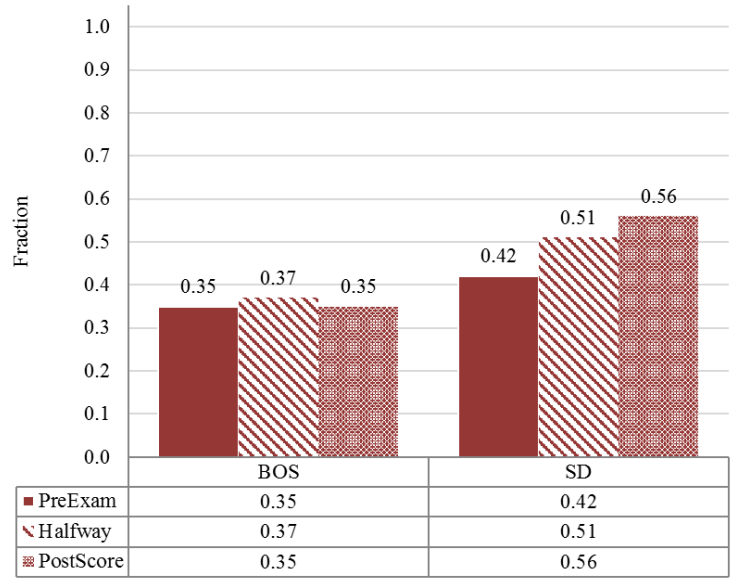

(b) Aptitude-Stably Matched Pairs

Figure 3: Score-Stably and Aptitude-Stably Matched Pairs

According to Figure 3a, there is a smaller proportion of score-stably matched pairs under PreExam-BOS or Halfway-BOS compared to the other four mechanisms $(p<0.001) .{ }^{24}$ As for the aptitude-stably matched pairs presented in Figure 3b, PreExam-BOS yields a smaller proportion of such pairs than Halfway-SD $(p=0.05)$ and PostScore-SD $(p=0.016)$. Similarly, there is also a smaller proportion under Halfway-BOS compared to Halfway-SD $(p=0.076)$ and PostScore-SD $(p=0.026){ }^{25}$

To sum up, the results regarding market outcomes confirm the theoretical predictions on score-stability but largely contradict the predictions on aptitude-stability under Assumption 4 (common knowledge of no over- or underplacement). In particular, not only do PreExamBOS and Halfway-BOS fail to achieve aptitude-stability but they also create more severe distortions from aptitude-stability compared to Halfway-SD and PostScore-SD.

\subsubsection{Overconfidence}

To trace the reason behind the above-mentioned market failures under PreExam-BOS and Halfway-BOS, I first examine the existence and heterogeneity of subjects' self-evaluation biases. Since rank is a much more relevant notion than score in the current setting, below I use overplacement as the primary measure of overconfidence. Recall $r_{a_{i}}$ ("AptitudeRank") refers to a student's rank of aptitude; $\epsilon_{i}$ ("ExamError") refers to an exam's measurement error in terms of rank; $\theta_{i}^{E A}$ ("OverconfidenceEA") and $\theta_{i}^{I N}$ ("OverconfidenceIN") are defined as a

\footnotetext{
${ }^{24}$ All of the proportion tests comparing PreExam-BOS (or Halfway-BOS) to PreExam-SD, to Halfway-SD, and to PostScore-SD yield a $p$-value smaller than 0.001. The McNemar's test comparing PreExam-BOS (or Halfway-BOS) to PostScore-BOS yields a $p$-value smaller than 0.001 .

${ }^{25}$ The $p$-values are from proportion tests.
} 
subject's level of overplacement at the ex-ante stage and the interim stage. ${ }^{26}$

Hypothesis 2. (i) No student exhibits any over-or underconfidence. (ii) Every student believes that other students exhibit no over- or underconfidence.

Result 3. At both ex-ante and interim stages, (i) students exhibit overconfidence on average;

(ii) men exhibit more overconfidence than women.

The average level of overplacement is 0.50 rankings at the ex-ante stage and is 0.26 at the interim stage. Since both values are significantly greater than zero ( $p<0.001$, t tests), students exhibit overconfidence at both stages. Moreover, $\theta_{i}^{E A}$ is significantly larger than $\theta_{i}^{I N}$ on average $(p<0.001$, paired $\mathrm{t}$ and sign test $) .{ }^{27}$ Figure 4 compares the distributions of $\theta_{i}^{E A}$ and $\theta_{i}^{I N}$ to the distribution of the exam's measurement error $\epsilon_{i}$. While all three variables exhibit similar variances, $\epsilon_{i}$ has a significantly larger mass on zero compared to $\theta_{i}^{E A}$ $\left(p<0.001\right.$, McNemar's test) or $\theta_{i}^{I N}$ ( $p=0.042$, McNemar's test). This provides us with some intuition behind Result 2: compared to the exam's measurement error, the behavioral error due to self-evaluation biases could lead to more mismatched pairs, that is, more severe distortions from aptitude-stability. ${ }^{28}$

\footnotetext{
${ }^{26}$ In Section 3.3.2, data from all six treatments are pooled together because in each treatment, subjects' guessed exam results are elicited at both ex-ante and interim stages. Moreover, as shown in Table 3, there is generally no significant treatment effect on overconfidence.

${ }^{27}$ There is no clear evidence that learning can reduce or eliminate self-evaluation biases. See a detailed analysis in Appendix B.1.

${ }^{28}$ Since overconfidence directly distorts the sorting in preference submission, not only the heterogeneity but also an overall tendency in self-evaluation biases will lead to distortions from aptitude-stability. On the other hand, the exam's measurement error in terms of rank has zero mean by construction.
} 


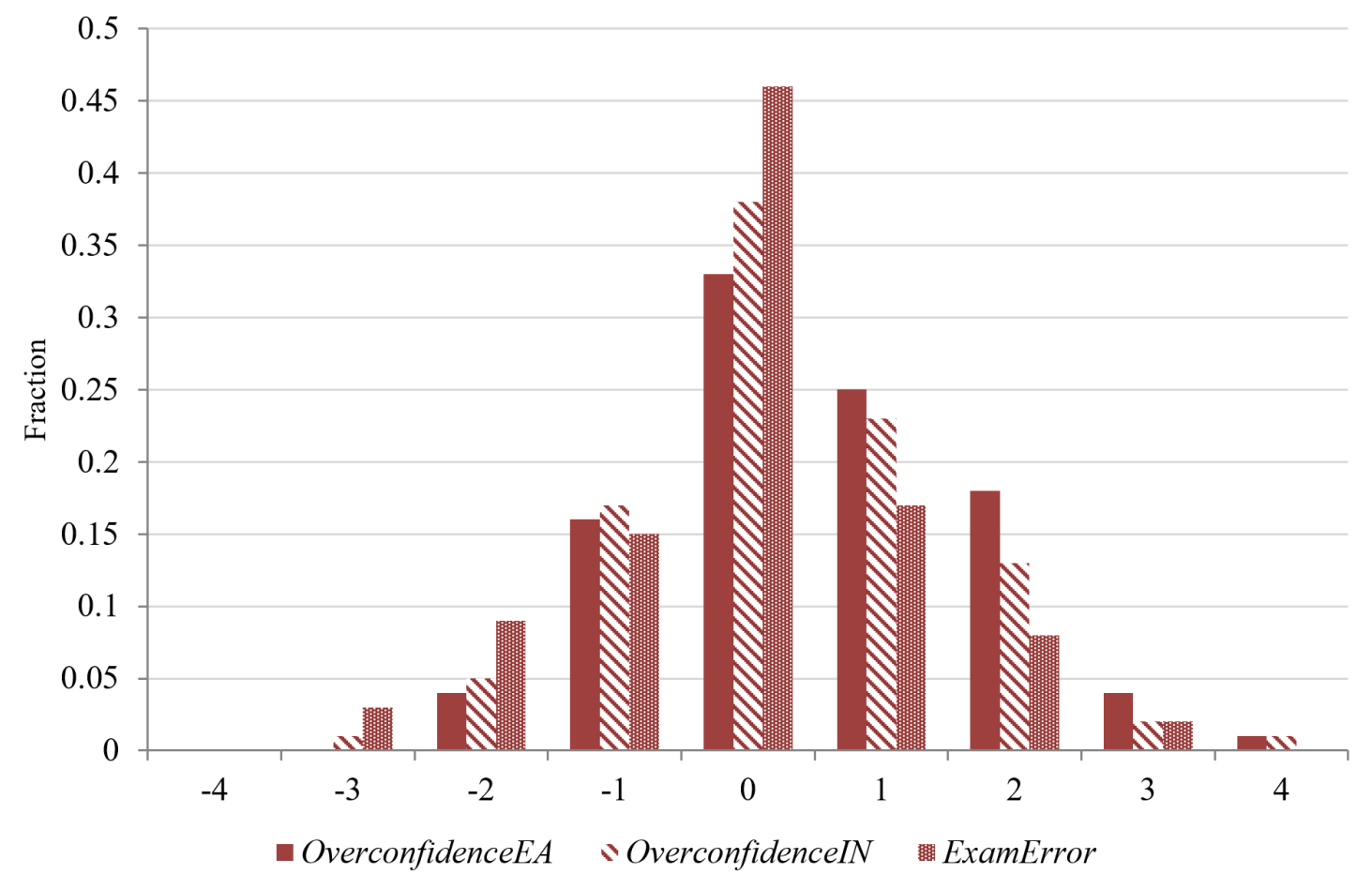

Figure 4: Distribution of OverconfidenceEA, OverconfidenceIN, and ExamError

To understand which factors can influence and thus predict a student's overconfidence level, I run an OLS regression of OverconfidenceEA and OverconfidenceIN, with the data clustered by subject. The results are displayed in Table 3 and briefly summarized as follows. First, men are more overconfident than women (the marginal effect of Female at the mean of RiskAverse is -0.184 at the ex-ante stage and is -0.113 at the interim stage; such a negative effect is more significant for more risk-averse subjects). Second, at the ex-ante stage, those who are less risk averse tend to be more overconfident, and the coefficient of the interaction term Female $\times$ RiskAverse indicates this effect is mainly driven by men. Third, students with lower aptitudes (larger values of AptitudeRank) exhibit more overconfidence. ${ }^{29}$ There are no consistent treatment effects (except the 10\%-level significance of PreExam-BOS and the 5\%-level significance of PostScore-BOS on OverconfidenceIN).

Recall at the end of the experiment, each subject is asked to estimate the levels of overplacement $\theta_{j}^{E A}$ and $\theta_{j}^{I N}$ for a randomly drawn other subject $j$; I refer to the estimates for $\theta_{j}^{E A}$ and $\theta_{j}^{I N}$ as "GuessedOtherEA" and "GuessedOtherIN". Result 4 suggests that subjects are not aware of the general tendency of overplacement.

Result 4. At both ex-ante and interim stages, subjects underestimate other students' average level of overconfidence.

\footnotetext{
${ }^{29}$ The correlation between aptitude and overconfidence may be partially driven by a ceiling effect: the student with the highest aptitude rank cannot have a positive level of overconfidence.
} 
Without any significant treatment effect, the average level of GuessedOtherEA is 0.03 and that of GuessedOtherIN is -0.21 . Comparing to the mean of $\theta_{i}^{E A}(0.50)$ and that of $\theta_{i}^{I N}$ (0.26), we conclude that on average, subjects underestimate others' overconfidence level at both ex-ante and interim stages $(p<0.001, \mathrm{t}$ tests $)$. Such a result provides evidence for Assumption $4^{\prime}$, which could be explained by the unawareness of one's own bias, together with the false-consensus effect.

Table 3: Predicting Factors of Overconfidence (OLS)

\begin{tabular}{r|cc|cc}
\hline Dep. Var. & \multicolumn{2}{|c|}{ OverconfidenceEA } & \multicolumn{2}{c}{ OverconfidenceIN } \\
\hline Female & $-1.008^{* *}$ & $(0.430)$ & $-0.974^{*}$ & $(0.500)$ \\
RiskAverse & $-0.074^{* * *}$ & $(0.020)$ & $-0.063^{* * *}$ & $(0.021)$ \\
Female $\times$ RiskAverse & $0.067^{* *}$ & $(0.033)$ & $0.070^{*}$ & $(0.037)$ \\
AptitudeRank & $0.603^{* * *}$ & $(0.044)$ & $0.525^{* * *}$ & $(0.046)$ \\
PreExam-BOS & 0.053 & $(0.167)$ & $0.321^{*}$ & $(0.183)$ \\
Halfway-BOS & -0.114 & $(0.167)$ & 0.154 & $(0.188)$ \\
PostScore-BOS & 0.053 & $(0.175)$ & $0.388^{* *}$ & $(0.185)$ \\
Halfway-SD & 0.022 & $(0.182)$ & 0.067 & $(0.183)$ \\
PostScore-SD & -0.133 & $(0.136)$ & 0.133 & $(0.140)$ \\
Constant & -0.330 & $(0.316)$ & $-0.714^{* *}$ & $(0.326)$ \\
\hline Observations & \multicolumn{3}{|c}{315} \\
\hline
\end{tabular}

Notes: Robust standard errors are shown in parentheses, allowing for clustering by subject. $* * *, * *$, and $*$ indicate significance at the $1 \%, 5 \%$, and $10 \%$ levels, respectively. In the regression, Female is a dummy variable that equals 1 for a female subject and 0 otherwise; RiskAverse is the total number of safe choices made by a subject during risk attitude elicitation; Female $\times$ RiskAverse is the interaction term between Female and RiskAverse; PreExam-BOS, Halfway-BOS, PostScore-BOS, Halfway-SD, and PostScore-SD are dummy variables for the corresponding treatments. The descriptive statistics of key variables are summarized in Table 9 of Appendix C.

\subsubsection{Preference Submission}

Besides belief biases, subjects' strategic deviations can also affect the performance of a mechanism. Recall in Section 2.4, I discussed three strategies under different treatments: truthtelling under PreExam-, Halfway-, and PostScore-SD; score-based sorting under PostScoreBOS; and guess-based sorting under PreExam- and Halfway-BOS. From the results below, we can see all three strategies are common in the experimental data.

Hypothesis 3. Students report their preferences truthfully under PreExam-, Halfway-, and PostScore-SD, exhibit score-based sorting under PostScore-BOS, and exhibit guess-based sorting under PreExam-BOS and Halfway-BOS. 
Result 5. Regardless of the timing of preference submission, more than $80 \%$ of the students report their preferences truthfully under $S D$, while more than $80 \%$ of the students misrepresent their preferences under BOS.

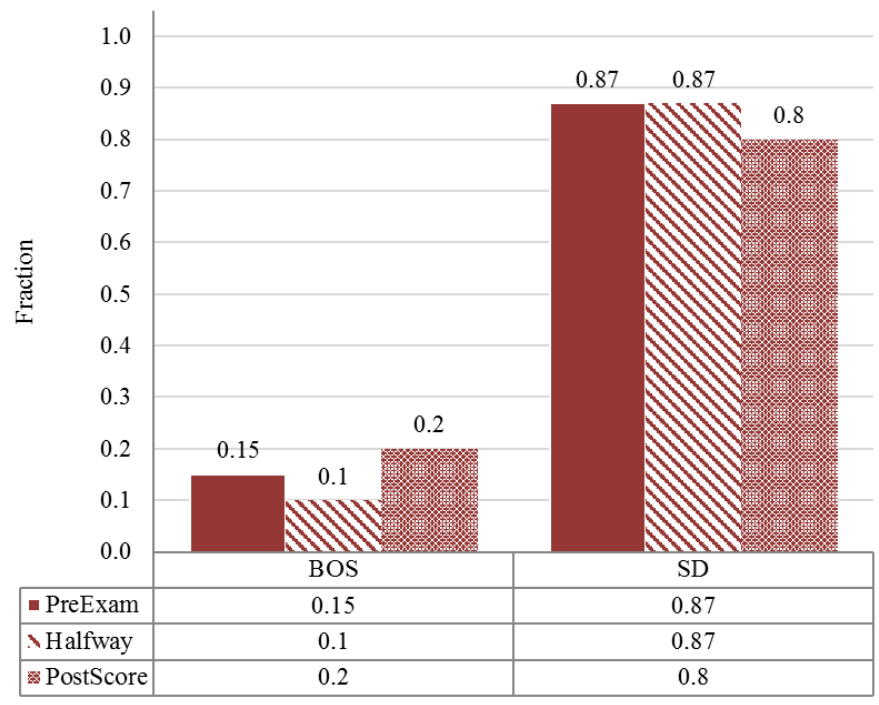

Figure 5: Truth-telling in Preference Submission

Figure 5 summarizes the proportions of truth-telling subjects under different mechanisms. As predicted by the model, truthful revelation dominates under SD, while preference misrepresentation dominates under BOS. The following result describes the general patterns of misrepresentation under BOS.

Result 6. (i) Under PostScore-BOS, about $70 \%$ of the students exhibit score-based sorting. (ii) Under PreExam-BOS and Halfway-BOS, students tend to exhibit guess-based sorting or adopt slightly more aggressive strategies than guess-based sorting.

To identify score-based or guess-based sorting under BOS, I focus on the variable FirstChoice, which is given by the index of the college listed on top of one's submitted preferences. For example, FirstChoice $=3$ if a subject chooses college $c_{3}$ as the first choice. Moreover, recall the variables $r_{s_{i}}$ ("Rank"), $\hat{r}_{s_{i}}^{E A}$ ("GuessedRankEA"), and $\hat{r}_{s_{i}}^{I N}$ ("GuessedRankIN") are defined as one's realized rank, guessed rank at the ex-ante stage, and guessed rank at the interim stage, respectively.

Under PostScore-BOS, a subject is said to exhibit score-based sorting in the experiment if FirstChoice $=r_{s_{i}}$, because the index of the subject's score-stably matched college equals $r_{s_{i}}$. Figure $6 \mathrm{c}$ is a bubble chart that shows the relationship between FirstChoice and $r_{s_{i}}$ under PostScore-BOS; the size of each bubble is determined by frequency. We can see that a 
majority of the data is on the 45-degree line, meaning most subjects $(71.67 \%)$ exhibit scorebased sorting. The bubbles under the 45-degree line represents those who adopt a more aggressive strategy since FirstChoice $<r_{s_{i}}$, that is, the college of one's first choice is more desirable than his or her score-stable match. Most students with such a strategy are ranked 5 th in the exam. ${ }^{30}$

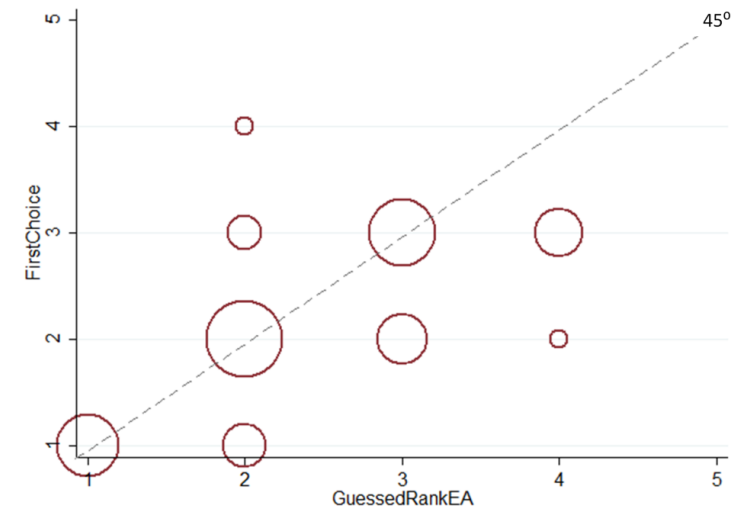

(a) Guess-based sorting under PreExam-BOS

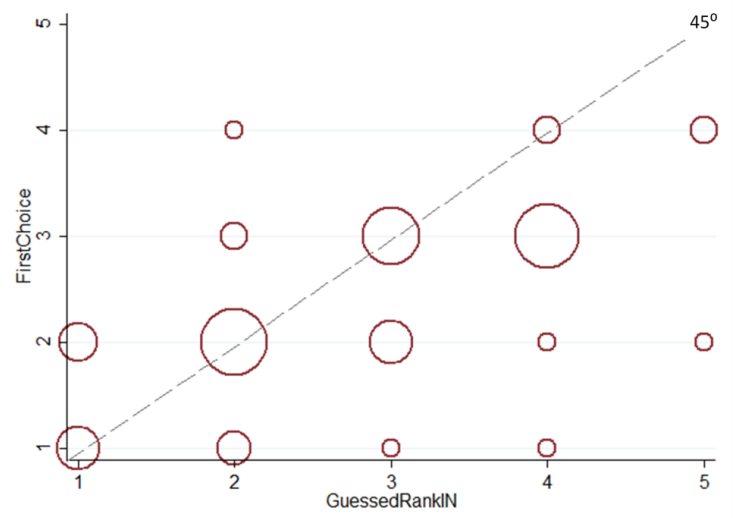

(b) Guess-based sorting under Halfway-BOS

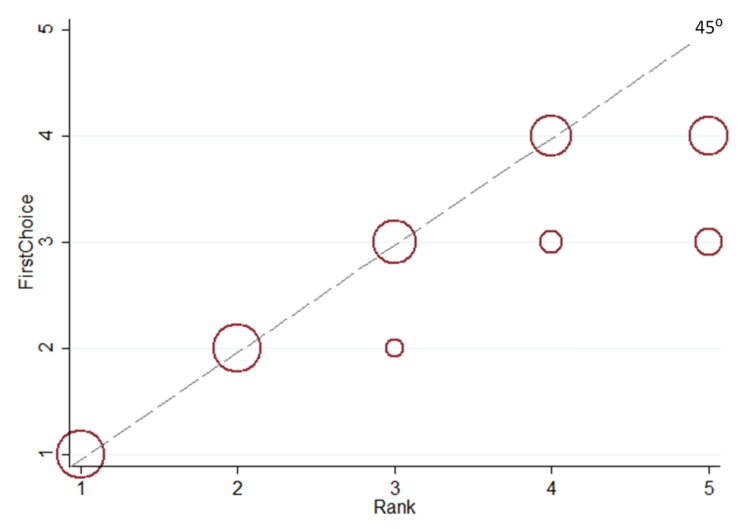

(c) Score-based sorting under PostScore-BOS

Figure 6: Preference Submission under BOS

Under PreExam-BOS, a student is said to exhibit guess-based sorting if FirstChoice $=\hat{r}_{s_{i}}^{E A}$. $61.67 \%$ of the subjects use this strategy (see bubbles on the 45 -degree line of Figure 6a). We also observe a considerable mass $(30 \%)$ on FirstChoice $=\hat{r}_{s_{i}}^{E A}-1$, indicating a slightly more aggressive strategy than guess-based sorting. Similar patterns are observed under HalfwayBOS (Figure 6b). While $46.67 \%$ of the students adopt guess-based sorting with FirstChoice $=\hat{r}_{s_{i}}^{I N}, 35 \%$ of them exhibit FirstChoice $=\hat{r}_{s_{i}}^{I N}-1$.

\footnotetext{
${ }^{30}$ This confirms the theoretical prediction that under the current setting, students ranked 5 th in the exam are indifferent between all strategies in equilibrium (see the proof of Proposition 2 in Appendix A).
} 
The aforementioned aggressive strategic choices suggest that subjects tend to be overoptimistic about the extent of competition in the market. In an environment with more uncertainty, like PreExam- or Halfway-BOS, they appear to be gambling on the chance that no others will choose more desirable colleges as their first choice, leaving them the opportunity to get in. From the subsequent regression analysis (Table 4), we will be able to examine whether such behaviors are related to one's beliefs about other students' over- or underconfidence levels.

Result 7. (i) Under PreExam-BOS and Halfway-BOS, a subject's first choice in preference submission is predicted by his or her aptitude rank and overconfidence level. (ii) Under PostScore-BOS, a subject's first choice is predicted by his or her aptitude rank and the exam's measurement error.

Table 4 displays the results for ordered logit regressions of FirstChoice under (1) PreExamBOS, (2) Halfway-BOS, and (3) PostScore-BOS. ${ }^{31}$ Regression (3) shows significant effects of both AptitudeRank and ExamError on FirstChoice under PostScore-BOS. Since by definition, an exam outcome is composed of one's aptitude together with a measurement error, such a result echoes the fact that a majority of subjects exhibit score-based sorting (Result 6).

Now I focus on treatments PreExam-BOS and Halfway-BOS. First, by regressions (1) and (2), a subject with a higher level of overconfidence (an increase in OverconfidenceEA or OverconfidenceIN) or a better rank of aptitude (a decrease in AptitudeRank) tends to choose a more desirable college as the first choice (a decrease in FirstChoice). Significant marginal effects for each outcome are displayed in Table 10 of Appendix C. For example, under PreExam-BOS, a subject is $30.1 \%$ more likely to choose the best college $c_{1}$ as the first choice if his or her overplacement is increased by one rank; a subject is $26.9 \%$ less likely to choose $c_{1}$ if his or her aptitude is placed one rank worse in the market. Hence, not only aptitudes, but also overconfidence levels enter students' strategic choices, thus influencing the performance of these two mechanisms.

Second, by regressions (1) and (2), GuessedOtherEA, GuessedOtherIN, and RiskAverse do not have any significant influence on FirstChoice. Recall that under PreExam- and HalfwayBOS, a considerable number of subjects adopt more aggressive strategies than guess-based sorting. Apparently, such behaviors are not correlated with risk attitudes and cannot be rationalized by beliefs on others' overconfidence levels. Therefore, optimism is displayed on two levels: not only are subjects overconfident in guessing the exam outcomes, but also they tend to "shoot for the stars" in preference submission.

\footnotetext{
${ }^{31}$ In the regressions, I exclude all variables that a subject does not observe at the time of preference submission. For example, OverconfidenceIN is excluded from regression (1), because preferences are submitted before the guess at the interim stage. The conclusions remain unchanged if these variables are included.
} 
Table 4: First Choice in Preference Submission (Ordered Logit)

\begin{tabular}{r|c|c|c}
\hline Dep. Var. & \multicolumn{3}{|c}{ FirstChoice } \\
\hline & $(1)$ & $(2)$ & $(3)$ \\
& PreExam-BOS & Halfway-BOS & PostScore-BOS \\
\hline OverconfidenceEA & $-2.687^{* * *}$ & $-1.320^{* * *}$ & -0.507 \\
& $(0.523)$ & $(0.448)$ & $(0.516)$ \\
OverconfidenceIN & & $-0.984^{* *}$ & -0.704 \\
& & $(0.379)$ & $(0.494)$ \\
AptitudeRank & $2.391^{* * *}$ & $2.214^{* * *}$ & $4.691^{* * *}$ \\
& $(0.482)$ & $(0.429)$ & $(0.958)$ \\
ExamError & & & $-4.307^{* * *}$ \\
& & & $(0.848)$ \\
GuessedOtherEA & 0.246 & 0.120 & 0.030 \\
& $(0.215)$ & $(0.207)$ & $(0.277)$ \\
GuessedOtherIN & & -0.131 & $0.595^{*}$ \\
& & $(0.240)$ & $(0.360)$ \\
RiskAverse & 0.054 & -0.049 & 0.043 \\
& $(0.070)$ & $(0.065)$ & $(0.081)$ \\
\hline Observations & 60 & 60 & 60 \\
\hline
\end{tabular}

Notes: Standard errors are shown in parentheses. $* * *, * *$, and $*$ indicate significance at the $1 \%$, $5 \%$, and $10 \%$ levels, respectively.

\subsubsection{Individual Welfare}

To measure how much a student's welfare is distorted from the aptitude-stable matching, I define the variable WelfareDistortion as AptitudeRank - which equals the index of one's aptitude-stably matched college - minus the index of one's currently matched college. A positive value of WelfareDistortion indicates that a student is allocated to a college with a smaller index than his or her aptitude-stable match, which means the current mechanism is giving the student an "unfair" advantage that cannot be justified by his or her aptitude.

The distributions of WelfareDistortion under different treatments are illustrated in Figure 7. We can clearly see a smaller mass at 0 under PreExam- and Halfway-BOS compared to Halfway- and PostScore-SD. Such a conclusion has already been drawn in Result 2, stating that PreExam- and Halfway-BOS tend to yield a smaller proportion of aptitude-stably matched pairs. In addition, the distribution under PostScore-SD exhibits a smaller variance compared to those under PreExam-BOS ( $p=0.006$, variance ratio test) and Halfway-BOS ( $p=0.040$, variance ratio test). 

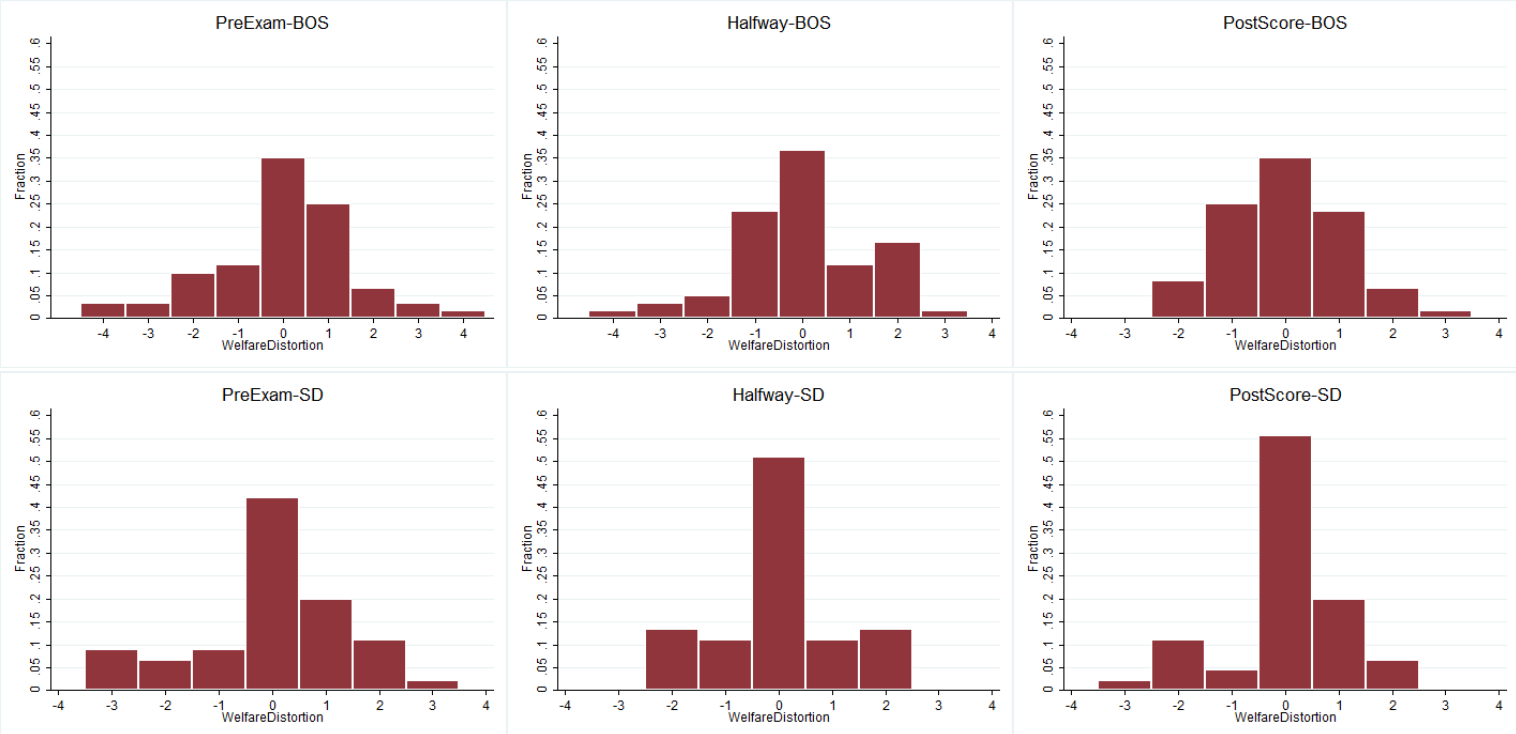

Figure 7: Distributions of Individual Welfare Distortion from Aptitude-Stability
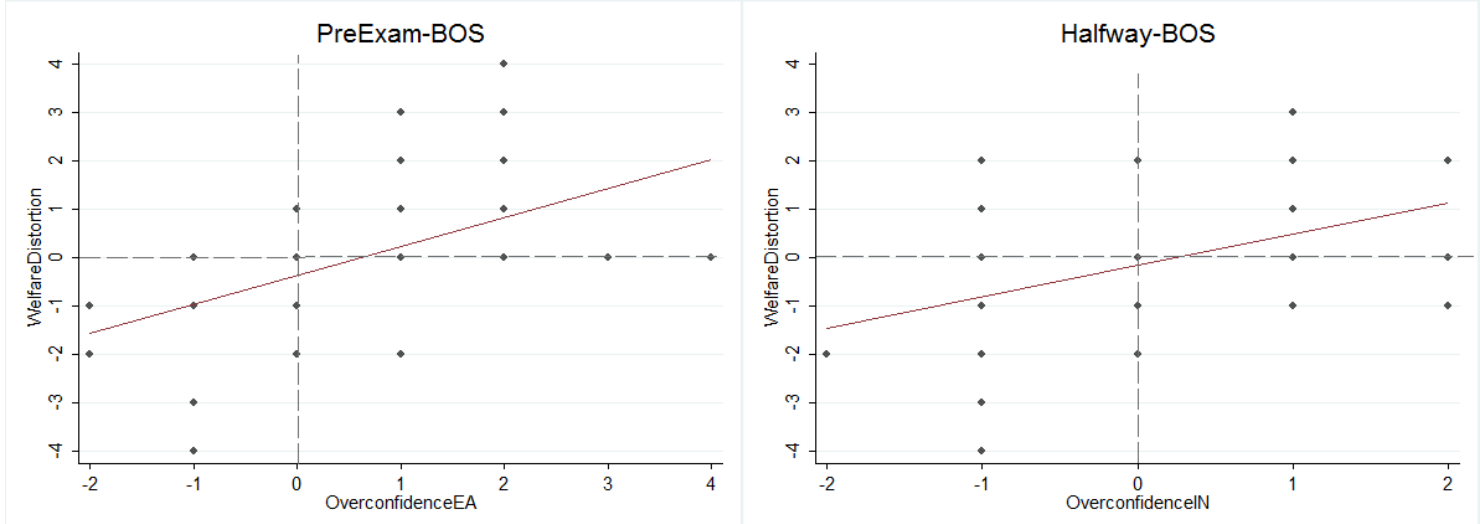

Figure 8: Overconfidence and Individual Welfare Distortion

As shown in Section 2.4, being overconfident under PreExam- or Halfway-BOS could hurt or benefit a student's welfare, depending on the distribution of overconfidence and the realization of the exam's measurement error in the market. Figure 8 helps us to take a first look at the relationship between overconfidence and individual welfare in the experimental data. Both graphs exhibit a generally positive correlation, which means PreExam- and HalfwayBOS tend to reward those who are overconfident and punish those who are underconfident. Combined with the the fact that men are more overconfident than women (Result 3), we can conclude males tend to receive an unfair advantage under these two mechanisms. ${ }^{32}$ Figure

\footnotetext{
${ }^{32}$ This conclusion also uses the fact that gender does not impose a direct effect on WelfareDistortion (see regressions (1) and (2) in Table 5).
} 
9 clearly shows that the gender difference in overconfidence (Figure 9a) is translated into a gender penalty for women in terms of individual welfare (Figure 9b) under PreExam- and Halfway-BOS.

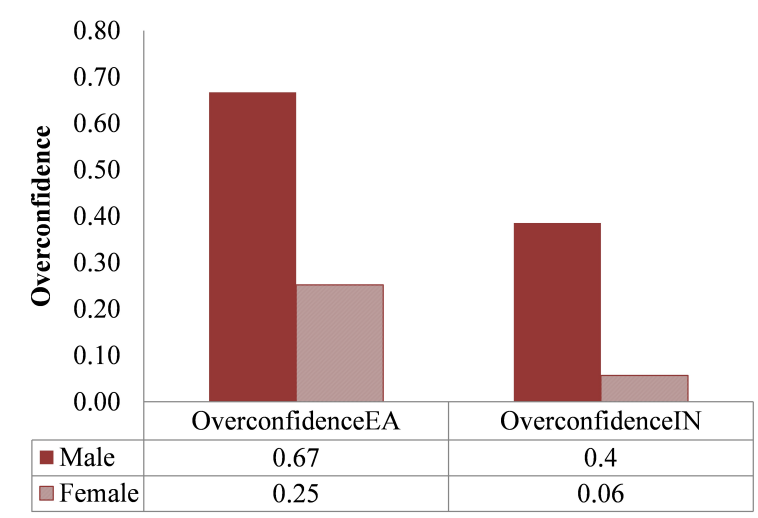

(a) Average Overconfidence by Gender

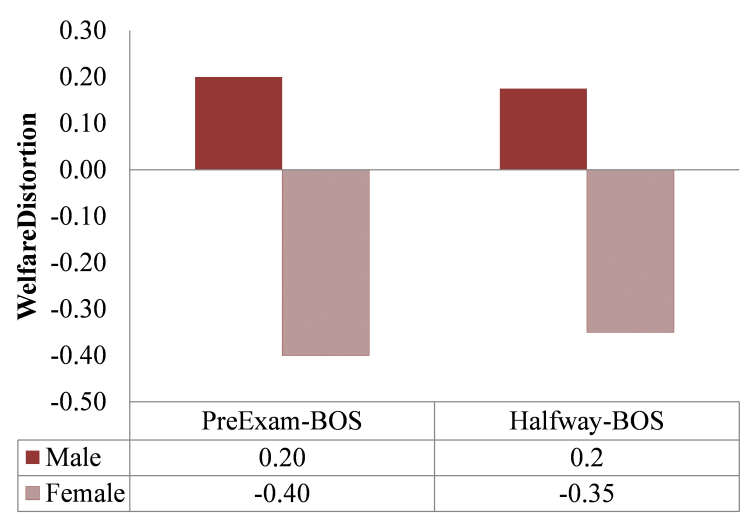

(b) Average WelfareDistortion by Gender

Figure 9: Gender Penalty under PreExam-BOS and Halfway-BOS

To obtain specific marginal effects, I run an OLS regression of WelfareDistortion under (1) PreExam-BOS, (2) Halfway-BOS, and (3) PostScore-BOS. ${ }^{33}$ The main results are summarized as follows.

Result 8. On an individual level, PreExam-BOS and Halfway-BOS create more severe and more varied distortions from aptitude-stability than PostScore-SD. Such distortions are affected by one's overconfidence level and strategic choice, as well as the exam's measurement error. Specifically, a student tends to be matched to a better college if

(i) he or she exhibits a higher level of overconfidence,

(ii) he or she performs better in the exam, or

(iii) he or she adopts a more aggressive strategy in preference submission.

Regression (3) in Table 11 shows that ExamError significantly and positively affects $W e l-$ fareDistortion. This means under PostScore-BOS, students' performance on one exam has a direct influence on their welfare, which is not surprising given the strong evidence for scorebased sorting (Result 6).

Recall in Section 2.4, I use Example 1 to illustrate that under PreExam- and HalfwayBOS, the presence of overconfidence can cause welfare distortions both directly (it distorts the sorting in preference submission) and indirectly by bringing back the noise of the exam's measurement error (it creates conflicts in submitted preferences, thus forcing BOS to resolve

\footnotetext{
${ }^{33}$ Tables 11 and 12 in Appendix C present the ordered logit regressions of WelfareDistortion and the significant marginal effects.
} 
them using exam scores). Such an intuition is well supported by regressions (1) and (2), in which both OverconfidenceEA (or OverconfidenceIN) and ExamError impose a significant influence on WelfareDistortion under PreExam-BOS (or Halfway-BOS). On average, if a student's level of overplacement is increased by one, his or her WelfareDistortion rises by 0.493 under PreExam-BOS and by 0.789 under Halfway-BOS; if a student's score rank in the exam is increased by one, his or her WelfareDistortion increases by 0.379 under PreExam-BOS and by 0.288 under Halfway-BOS. ${ }^{34}$

Table 5: Individual Welfare Distortion (OLS)

\begin{tabular}{r|c|c|c}
\hline Dep. Var. & \multicolumn{3}{|c}{ WelfareDistortion } \\
\hline & $(1)$ & $(2)$ & $(3)$ \\
& PreExam-BOS & Halfway-BOS & PostScore-BOS \\
\hline OverconfidenceEA & $0.493^{* * *}$ & -0.217 & -0.024 \\
& $(0.143)$ & $(0.252)$ & $(0.076)$ \\
EverconfidenceIN & & $0.789^{* * *}$ & 0.086 \\
& & $(0.250)$ & $(0.084)$ \\
EggressiveStrategy & $0.379^{* *}$ & $0.288^{* *}$ & $0.943^{* * *}$ \\
& $(0.156)$ & $(0.123)$ & $(0.074)$ \\
GuessedOtherEA & $0.689^{* * *}$ & $0.423^{*}$ & -0.025 \\
& $(0.259)$ & $(0.224)$ & $(0.131)$ \\
GuessedOtherIN & 0.172 & 0.166 & -0.002 \\
& $(0.105)$ & $(0.120)$ & $(0.046)$ \\
RiskAverse & & -0.089 & 0.043 \\
& 0.020 & $(0.142)$ & $(0.059)$ \\
Female & $(0.040)$ & 0.057 & 0.024 \\
& -0.009 & $(0.039)$ & $(0.015)$ \\
Constant & $(0.371)$ & -0.304 & 0.025 \\
& -0.772 & $(0.330)$ & $(0.144)$ \\
& $(0.523)$ & $-0.834^{*}$ & -0.288 \\
Observations & 60 & $(0.493)$ & $(0.197)$ \\
\hline
\end{tabular}

Notes: Standard errors are shown in parentheses. ***,**, and $*$ indicate significance at the $1 \%$, $5 \%$, and $10 \%$ levels, respectively.

Besides biases in beliefs, we also observe a considerable proportion of students adopt strategies other than guess-based sorting under PreExam- and Halfway-BOS. To measure the extent of such a deviation, I define the variable AggressiveStrategy as GuessedRankEA (or GuessedRankIN) minus FirstChoice under PreExam-BOS (or Halfway-BOS). A positive

\footnotetext{
${ }^{34}$ See Appendix B.2 for a detailed discussion on the correlation between overconfidence and the exam's measurement error.
} 
value of AggressiveStrategy indicates a strategy more aggressive than guess-based sorting, because the college of one's first choice is more desirable than his or her score-stable match. According to regressions (1) and (2), a more aggressive strategy tends to have a significant and positive effect on individual welfare. On average, a unit increase in AggressiveStrategy raises WelfareDistortion by 0.689 under PreExam-BOS and by 0.423 under Halfway-BOS. Under PostScore-BOS, AggressiveStrategy is defined as Rank minus FirstChoice and measures the extent of a deviation from score-based sorting. Since a majority of subjects adopt the equilibrium strategy under PostScore-BOS, AggressiveStrategy does not exhibit a significant effect in regression (3). Figure 17 in Appendix $\mathrm{C}$ categorizes observations along two dimensions: (i) whether a subject's belief is unbiased, underconfident, or overconfident, and (ii) whether a subject's strategy follows guess-based sorting, is more conservative than guessbased sorting, or is more aggressive than guess-based sorting; the fraction of each category in the experimental data is presented.

\subsection{No Effects of Additional Information}

The above results clearly suggest that under PreExam- and Halfway-BOS, overconfidence serves as a major obstacle to the implementation of an aptitude-stable matching. In this section, I explore whether an improved information condition could help to reduce overconfidence and thus enhance the performance of these two mechanisms. While a detailed description is given in Appendix B.3, below I briefly introduce the design and summarize the main results and implications.

In the new environment, after being re-grouped at the beginning of each treatment, every subject is provided with all of the past performances of his or her new group members, including their scores in the three mock tests and in all of the exams they have taken in the previous treatments. The average score of each member is calculated and displayed as well. ${ }^{35}$

The data show that the provision of such additional information has very little influence over subjects' levels of overconfidence, their strategic behaviors, and the market outcomes. This is a rather negative result since it indicates that the biases observed before mainly stem from one's belief about herself and thus cannot be reduced even with very detailed information regarding the rest of the market. Therefore, it implies a even bigger challenge to PreExamand Halfway-BOS in some field environments. For example, in Chinese college admissions, since mock tests are mostly created and organized by different high schools, students can-

\footnotetext{
${ }^{35}$ Recall in each session of the original design, about 15 participants are randomly divided into groups of five and are re-grouped for every mock test and every treatment. From the results of the three mock tests, subjects should be able to obtain a relatively clear picture of their aptitude ranking. However, for each treatment they do not receive any specific information on the other four group members. Under such a setting, there exist two major sources of overconfidence: overconfidence about the group composition ("I might be grouped with less smart people in this exam") and overconfidence about one's own performance ("I can score higher in this exam"). The new information condition is essentially muting the former while keeping the latter.
} 
not obtain direct information on the percentile of their scores in the entire market. In this case, the conclusion of this section raises the possibility that even under a more transparent information environment, the performance of PreExam- and Halfway-BOS still cannot be improved because self-evaluation biases may remain at the same level.

\section{Conclusion}

Many centralized college admissions markets adopt a standardized exam to evaluate students' aptitudes and determine students' priorities in the matching procedure. Since every exam entails a measurement error, the exam-based priorities can only serve as a noisy proxy for colleges' aptitude-based preferences. Previous literature suggests that the effect of this noise can be diminished with a "PreExam-BOS" mechanism (a Boston algorithm combined with preference submissions before the exam). Using a laboratory experiment, this paper provides evidence that the performance of PreExam-BOS may be affected by certain behavioral attributes of the market participants: (i) since pre-exam preference submission is distorted by overconfidence, PreExam-BOS creates more severe and more varied welfare distortions than the PostScore-SD mechanism (a Serial Dictatorship algorithm combined with preference submissions after the revelation of exam results); (ii) PreExam-BOS exhibits a tendency to reward overconfidence and punish underconfidence; (iii) since the experimental data show that women exhibit less overconfidence than men, PreExam-BOS serves on average as a gender penalty for women in the current laboratory sample. The paper also indicates that overconfidence mainly stems from one's belief about herself and thus cannot be easily mitigated with improved information regarding the rest of the market.

Admittedly, the laboratory study has its limitations in providing general predictions for complex field environments. However, this is not the main purpose of the present paper. Instead, this study aims to introduce a behavioral perspective and to modestly present a tradeoff that can emerge in real markets. The result of such a tradeoff depends on the actual distribution of overconfidence and the specific realization of the exam's measurement error. Therefore, regarding the choice of a matching mechanism for a specific market of interest, the findings of this paper call for a field investigation before drawing any conclusions. Specifically, we can benefit from a thorough study that takes various aspects into consideration, including the behavioral attributes and strategic patterns of the participating agents, the nature of the standardized exam, and institutional features of the market.

Another important question that this study leaves unanswered is how the market outcome might respond to different distributions of overconfidence and of the exam's measurement error. Laboratory experiments provide us with a powerful tool for such investigation. For example, the finding that people tend to be overconfident on easy tasks while they are underconfident on difficult tasks was used by Dargnies, Hakimov, and Kübler (2016) to create 
overall over- and underconfidence in the laboratory. A similar approach to manipulate the behavioral bias may shed some light on its effect on market outcomes.

Finally, the experimental results in this paper suggest that although preferable to PreExamBOS, PostScore-SD is still largely affected by the exam's measurement error. This implies a challenge in attempting to obtain a fair market outcome when students are evaluated with a single standardized exam. Thus, the findings of this paper point to a need for policymakers to weigh the benefits and costs when adopting such a noisy evaluation system. In practice, similar systems exist in various environments, including public school choice, college admissions, and labor market clearinghouses. This prevalence calls for more research in the future. In addition to the behavioral aspects considered in this paper, more issues such as heterogeneous preferences, asymmetric information, and constrained choices in preference submission should also be added to the discussion. 


\section{References}

Abdulkadiroğlu, A., Y.-K. Che, and Y. Yasuda (2011). Resolving conflicting preferences in school choice: The "boston mechanism" reconsidered. The American Economic Review, 399-410.

Abdulkadiroğlu, A. and T. Sönmez (2003). School choice: A mechanism design approach. The American Economic Review 93(3), 729-747.

Baldiga, K. (2013). Gender differences in willingness to guess. Management Science 60(2), $434-448$.

Barber, B. M. and T. Odean (2001). Boys will be boys: Gender, overconfidence, and common stock investment. Quarterly journal of Economics, 261-292.

Camerer, C. and D. Lovallo (1999). Overconfidence and excess entry: An experimental approach. The American Economic Review, 306-318.

Chen, Y. and O. Kesten (2017). Chinese college admissions and school choice reforms: A theoretical analysis. Journal of Political Economy 125(1), 99-139.

Chen, Y. and T. Sönmez (2006). School choice: an experimental study. Journal of Economic Theory 127(1), 202-231.

Coffman, K. B. (2014). Evidence on self-stereotyping and the contribution of ideas. The Quarterly Journal of Economics, 261-292.

Dargnies, M.-P., R. Hakimov, and D. Kübler (2016). Self-confidence and unraveling in matching markets. Technical report, WZB Discussion Paper.

Ergin, H. and T. Sönmez (2006). Games of school choice under the boston mechanism. Journal of Public Economics 90(1), 215-237.

Featherstone, C. R. and M. Niederle (2016). Boston versus deferred acceptance in an interim setting: An experimental investigation. Games and Economic Behavior 100, 353-375.

Gale, D. and L. S. Shapley (1962). College admissions and the stability of marriage. American Mathematical Monthly, 9-15.

Glaser, M. and M. Weber (2007). Overconfidence and trading volume. The Geneva Risk and Insurance Review 32(1), 1-36.

Haeringer, G. and F. Klijn (2009). Constrained school choice. Journal of Economic Theory $144(5), 1921-1947$.

Holt, C. A. and S. K. Laury (2002). Risk aversion and incentive effects. The American Economic Review 92(5), 1644-1655.

Jiang, M. (2014). When do stable matching mechanisms fail? the role of standardized tests in college admissions. Working Paper. 
Kesten, O. (2006). On two competing mechanisms for priority-based allocation problems. Journal of Economic Theory 127(1), 155-171.

Kleitman, S. and L. Stankov (2007). Self-confidence and metacognitive processes. Learning and Individual Differences 17(2), 161-173.

Klijn, F., J. Pais, and M. Vorsatz (2013). Preference intensities and risk aversion in school choice: A laboratory experiment. Experimental Economics 16(1), 1-22.

Lien, J. W., J. Zheng, and X. Zhong (2015). Preference submission timing in school choice matching: testing fairness and efficiency in the laboratory. Experimental Economics, $1-35$.

Lien, J. W., J. Zheng, and X. Zhong (2017). Ex-ante fairness in the boston and serial dictatorship mechanisms under pre-exam and post-exam preference submission. Games and Economic Behavior 101, 98-120.

Malmendier, U. and G. Tate (2005). Ceo overconfidence and corporate investment. The Journal of Finance 60(6), 2661-2700.

Marks, G. and N. Miller (1987). Ten years of research on the false-consensus effect: An empirical and theoretical review. Psychological Bulletin 102(1), 72.

Moore, D. A. and P. J. Healy (2008). The trouble with overconfidence. Psychological Review $115(2), 502$.

Niederle, M. and L. Vesterlund (2007). Do women shy away from competition? do men compete too much? The Quarterly Journal of Economics, 1067-1101.

Odean, T. (1999). Do investors trade too much? American Economic Review, 1279-1298.

Pais, J. and Á. Pintér (2008). School choice and information: An experimental study on matching mechanisms. Games and Economic Behavior 64 (1), 303-328.

Ross, L., D. Greene, and P. House (1977). The "false consensus effect": An egocentric bias in social perception and attribution processes. Journal of Experimental Social Psychology 13(3), 279-301.

Schaefer, P. S., C. C. Williams, A. S. Goodie, and W. K. Campbell (2004). Overconfidence and the big five. Journal of Research in Personality 38(5), 473-480.

Stankov, L. and J. D. Crawford (1996). Confidence judgments in studies of individual differences. Personality and Individual Differences 21(6), 971-986.

Wu, B. and X. Zhong (2014). Matching mechanisms and matching quality: Evidence from a top university in china. Games and Economic Behavior 84, 196-215. 


\section{Supplementary Material}

Appendix A includes proofs of Propositions 1 and 2. In Appendix B, I analyze learning behaviors in the experiments, discuss the correlation between the exam's measurement error and self-evaluation biases, and provide detailed results of the additional treatments with an improved information condition. Supplementary tables and figures can be found in Appendix C.

\section{Appendix A: Proofs}

\section{A.1. Proof of Proposition 1}

Proof. (1) In the current setting, where all colleges have the same strict priority ordering over students, the SD algorithm is a special case of the TTC algorithm. By Abdulkadiroğlu and Sönmez (2003), TTC is strategy-proof for any realized priority ordering over students. Therefore, truth-telling is a weakly dominant strategy for every student, regardless of the student's knowledge about the priority ordering at the time of preference submission. This proves the strategy-proofness of the PreExam-SD, Halfway-SD, and PostScore-SD mechanisms.

(2) By Kesten (2006), since the priority structure here satisfies the acyclic condition, the matching outcome of TTC is stable according to priorities. In addition, the uniqueness of such an outcome is proved by Haeringer and Klijn (2009). Translating into terms under the current setting, PostScore-SD always yield the score-stable matching outcome.

(3) From (1), we know in the truth-telling equilibrium, students' submitted preferences stay the same under PreExam-SD and Halfway-SD as those under PostScore-SD. And colleges' priority ordering depends only on students' exam score ranking. Therefore, given the fact that a matching algorithm only considers students' submitted preferences and colleges' priority ordering, the PreExam-SD and Halfway-SD also implement the score-stable matching outcome in the truth-telling equilibrium.

\section{A.2. Proof of Proposition 2}

Proof. Define the total number of seats at colleges $c_{1}, c_{2}, \ldots$, and $c_{k}$ as $Q_{k}=\sum_{j=1}^{k} q_{j}$.

First, for a student with score rank $r_{s_{i}}=1,2, \ldots$, or $Q_{1}$, it is a dominant strategy to list $c_{1}$ as her first choice. This is because she will be accepted by the best college $c_{1}$ regardless of other students' submitted preferences. Any other first choice will make her strictly worse off, because she will always be accepted by her first choice.

Given this, a student with score rank $r_{s_{i}}=Q_{1}+1, \ldots$, or $Q_{2}$ best responds by listing $c_{2}$ as the first choice. Deviating to $c_{1}$ will get him rejected in the first step and thus cannot make him better off. Any other first choice will make him strictly worse off. 
Similarly, it follows that a student with score rank $r_{s_{i}}=Q_{2}+1, \ldots$, or $Q_{3}$ best responds by listing $c_{3}$ as the first choice, a student with score rank $r_{s_{i}}=Q_{3}+1, \ldots$, or $Q_{4}$ best responds by listing $c_{4}$ as the first choice, and so on.

Finally, consider students with lowest score ranks $r_{s_{i}}=Q_{M}+1, \ldots, n$, where $Q_{M}<n$ and $Q_{M+1} \geq n$. Given other students' equilibrium strategies, these students are indifferent between all strategies that list $c_{M+1}$ above $c_{M+j}(j \geq 2)$.

(1) From the reasoning above, in any Nash equilibrium, students with $r_{s_{i}}=1, \ldots, Q_{1}$ list $c_{1}$ as the first choice; students with $r_{s_{i}}=Q_{1}+1, \ldots, Q_{2}$ list $c_{2}$ as the first choice; ...and students with $r_{s_{i}}=Q_{M-1}+1, \ldots, Q_{M}$ list $c_{M}$ as the first choice. Any remaining choices of these students and for students with $r_{s_{i}}=Q_{M}+1, \ldots, n$, any strategies that list $c_{M+1}$ above $c_{M+j}(j \geq 2)$ can exist in a Nash equilibrium. Therefore, those Nash equilibria where students with $r_{s_{i}}=Q_{M}+1, \ldots, n$ list $c_{M+1}$ as the first choice are the ones where every student exhibit score-based sorting.

(2) Given the characterization of students' equilibrium strategies, it is easy to see that all equilibria yield the same matching, where a student with $r_{s_{i}}=1, \ldots$, or $Q_{M}$ is assigned a seat at her first choice, and a student with $r_{s_{i}}=Q_{M}+1, \ldots$, or $n$ is assigned a seat at $c_{M+1}$. Such a matching is stable according to exam-based priorities or is score-stable.

\section{Appendix B: Additional Analysis}

\section{B.1. Learning and Overconfidence}

This section investigates whether students exhibit less self-evaluation biases as they become more experienced. In the experiment, treatments using the same algorithm are implemented within-subject, and under every treatment, subjects' beliefs about their performance on the exam are elicited at both the ex-ante and the interim stage. Therefore, I have three observations on each subject's ex-ante belief (OverconfidenceEA_1, OverconfidenceEA_2, OverconfidenceEA_3) and three on interim belief (OverconfidenceIN_1, OverconfidenceIN_2, OverconfidenceIN_3), from which I can investigate learning behaviors. ${ }^{36}$

\footnotetext{
${ }^{36}$ The order of treatments is randomized to ensure that learning does not interfere with any treatment effects.
} 


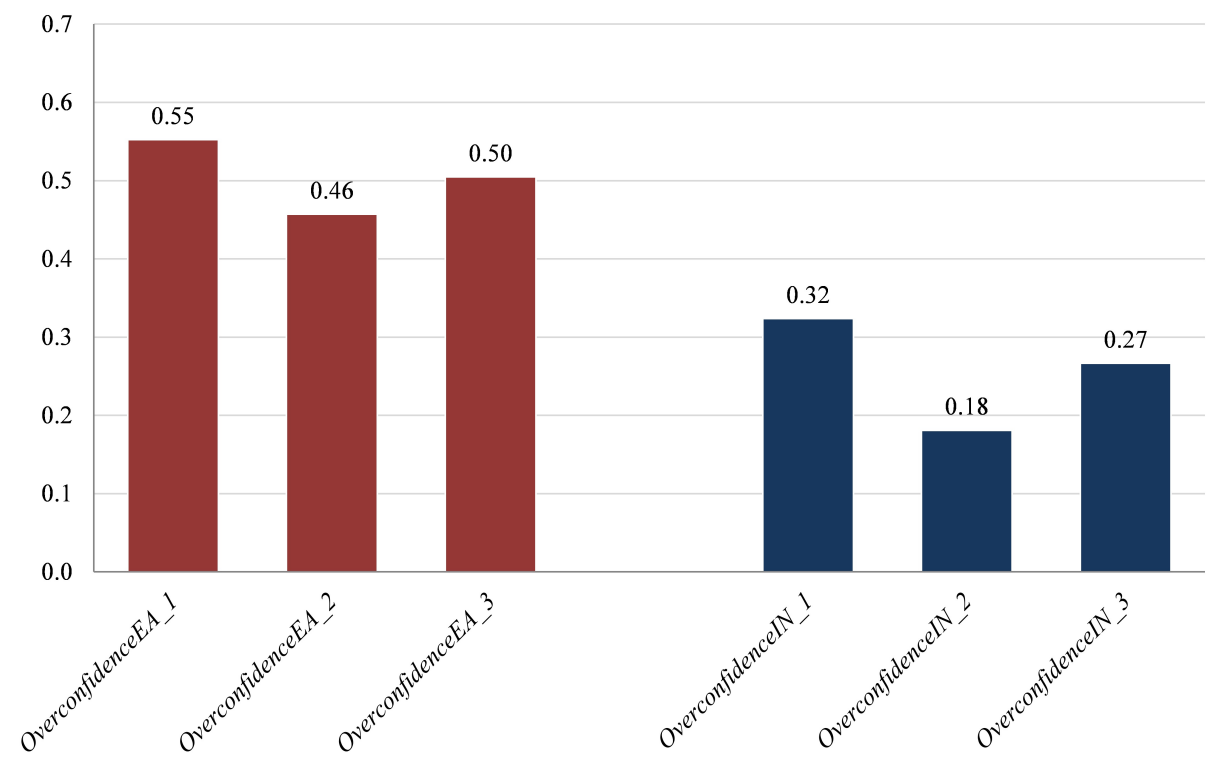

Figure 10: Three Observations of OverconfidenceEA and OverconfidenceIN (Mean)

As shown in Figure 10, there is not a clear downward trend in the average level of overconfidence. At the ex-ante stage, OverconfidenceEA_1 is greater than OverconfidenceEA_2 ( $p=0.01$, t test) but not than OverconfidenceEA_3 $(p=0.22$, t test $)$ on average. At the interim stage, OverconfidenceIN_1 is greater than OverconfidenceIN_2 ( $p<0.01$, t test) but OverconfidenceIN_2 is smaller than OverconfidenceIN_3 $(p=0.07$, t test) on average. All six values are significantly greater than zero $(p<0.001, \mathrm{t}$ tests $)$. In addition, these beliefs are from more experienced subjects since they are elicited after three mock tests and feedback. Hence, the laboratory data do not provide clear evidence that learning can reduce or eliminate self-evaluation biases.

\section{B.2. Overconfidence and The Exam's Measurement Error}

This section discusses the correlation between the exam's measurement error and the behavioral error due to self-evaluation biases. Such a correlation is not assumed away in the present paper, which is one of the reasons why the model gives an ambiguous prediction on the performance of PreExam- and Halfway-BOS, depending on the distribution of these two errors. 


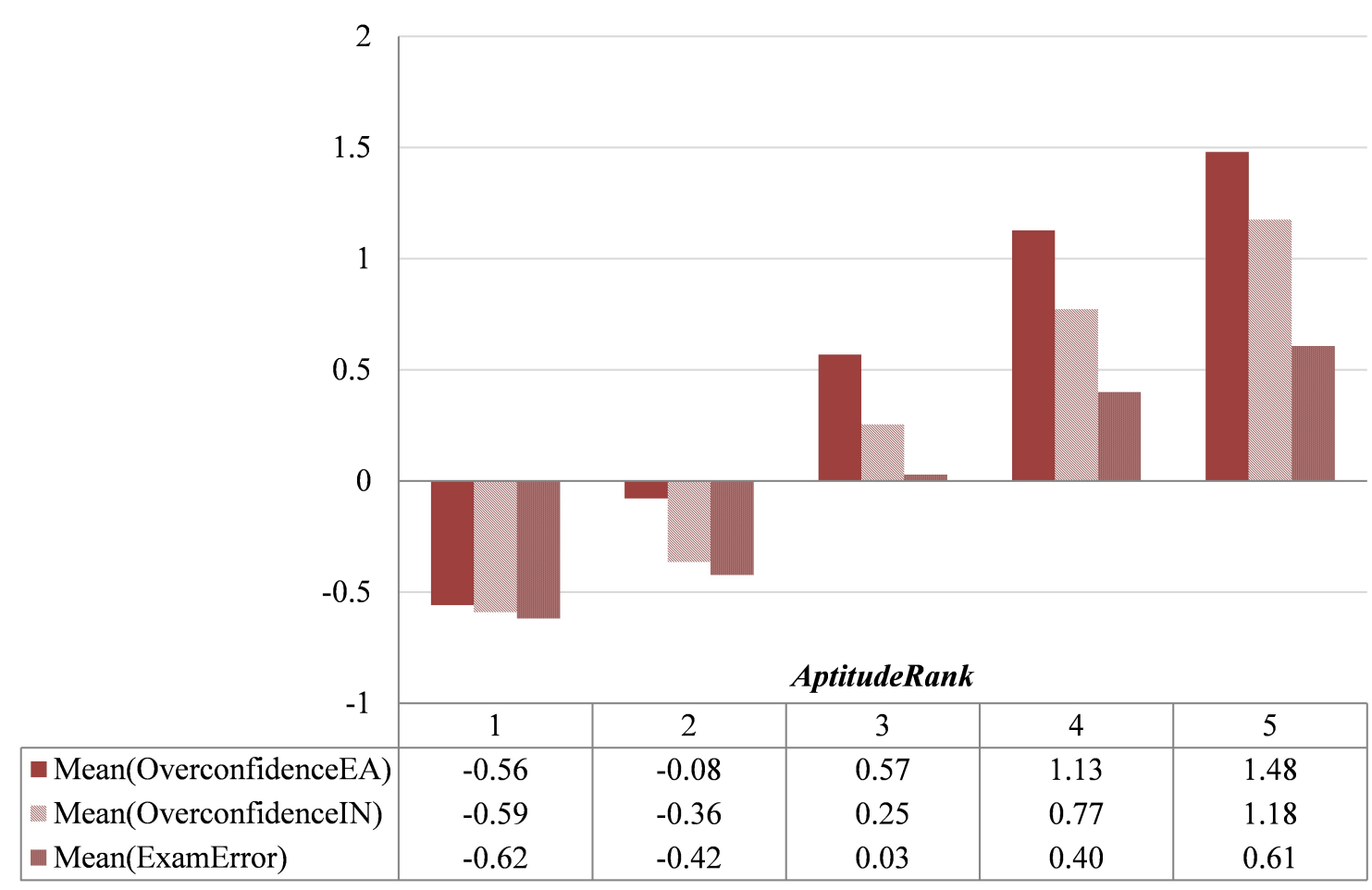

Figure 11: The Mean of OverconfidenceEA, OverconfidenceIN, and ExamError by AptitudeRank

In the experimental data, OverconfidenceEA and ExamError exhibit a positive correlation of 0.30, and OverconfidenceIN and ExamError exhibit a positive correlation of 0.34. This means the two errors reinforce each other in terms of welfare distortion: students who underperform in the exam are worse off on average; meanwhile, they tend to be less overconfident, which hurts them even more. Such a positive correlation can be largely explained by the fact that students with higher aptitudes are less overconfident and more likely to underperform in an exam (see the mean of OverconfidenceEA, OverconfidenceIN, and ExamError by the rank of aptitude in Figure 3). It can be overestimated in the laboratory environment because small markets impose a strong ceiling effect: the student with the highest aptitude rank cannot have a positive level of overconfidence or overperform in an exam. Such a ceiling effect may also exist in other environments but could be much weaker in a market with more students.

\section{B.3. Treatments with Additional Information}

The provision of additional information adds a third dimension to the original treatment design. From the overwhelming truth-telling behaviors under SD regardless the timing of 
preference submission, we can conclude that subjects' decision-making and the market outcomes are not affected by different information conditions. Therefore, I focus on the three mechanisms using BOS; the three new treatments with additional information are named "PreExam-BOS-INFO," "Halfway-BOS-INFO," and "PostScore-BOS-INFO," respectively. All of the other details of the experimental design and procedure are similar to those described in Sections 3.1 and 3.2. ${ }^{37}$

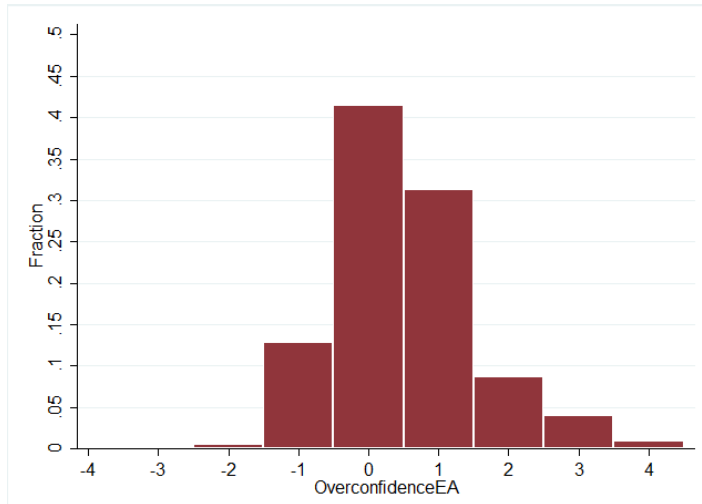

(a) Distribution of OverconfidenceEA $\theta_{i}^{E A}$

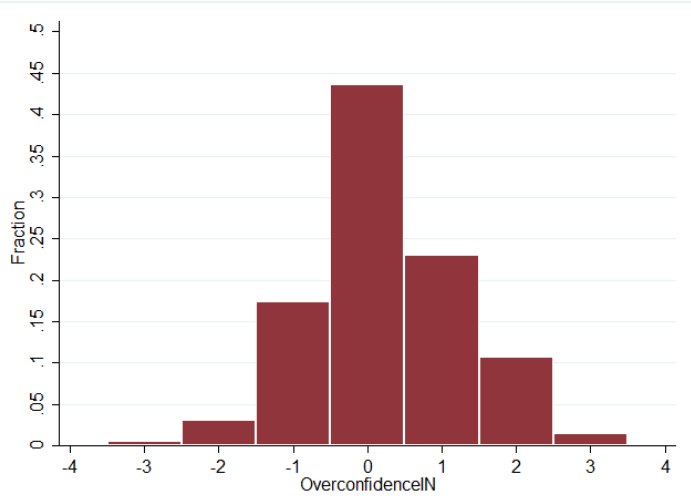

(b) Distribution of OverconfidenceIN $\theta_{i}^{I N}$

Figure 12: Levels of Overconfidence with Additional Information

Result 12. The provision of additional information fails to reduce the magnitude of overconfidence at either the ex-ante or interim stage.

Under the new treatments, subjects' average level of overplacement is 0.51 at the exante stage and is 0.24 at the interim stage. ${ }^{38}$ Comparing to the average without additional information ( 0.50 at the ex-ante stage and 0.26 at the interim stage), the magnitudes of biases are clearly not reduced $(p>0.44)$.

\footnotetext{
${ }^{37}$ For the new treatments, four additional sessions (one with 20 subjects, three with 15 subjects) were conducted in September 2015 at the Experimental Economics Laboratory of The Ohio State University. There were a total of 65 participants (22 females and 43 males).

${ }^{38}$ Again, data from all three treatments are pooled together since there is no significant treatment effect on overconfidence. Figure 12 shows the distributions of $\theta_{i}^{E A}$ and $\theta_{i}^{I N}$.
} 

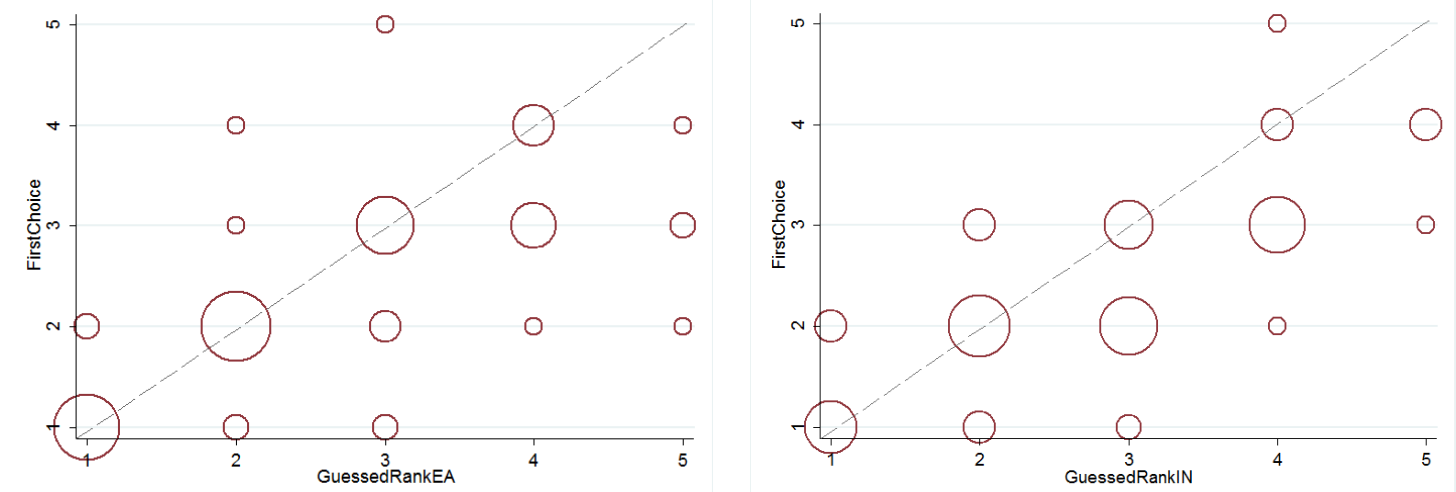

(a) Guess-based sorting under PreExam-BOS-INFO

(b) Guess-based sorting under Halfway-BOS-INFO

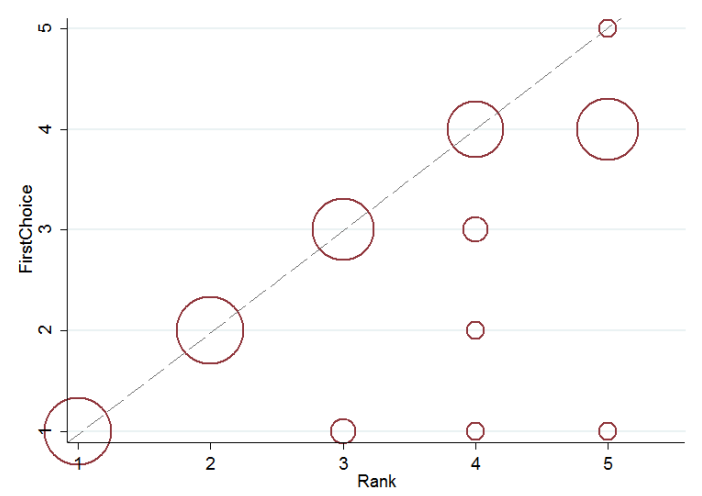

(c) Score-based sorting under PostScore-BOS-INFO

Figure 13: Preference Submission under BOS

Given the above result, together with the fact that subjects' strategic choices are not significantly affected by the additional information (Figure 13), we can expect that our conclusion regarding aptitude-stability remain unchanged.

Result 13. The provision of additional information fails to improve the performance of PreExam-BOS and Halfway-BOS: compared to PostScore-SD, they still create more severe and more varied distortions from aptitude-stability .

On the market level, aptitude-stability is rarely achieved under any of the three new treatments (except one market under PreExam-BOS-INFO). From Figure 14, we can see in terms of the proportion of aptitude-stably matched pairs, PreExam-BOS-INFO does not perform significantly better than PreExam-BOS $(p=0.36)$, while Halfway-BOS-INFO performs slightly worse than Halfway-BOS $(p=0.07)$. 


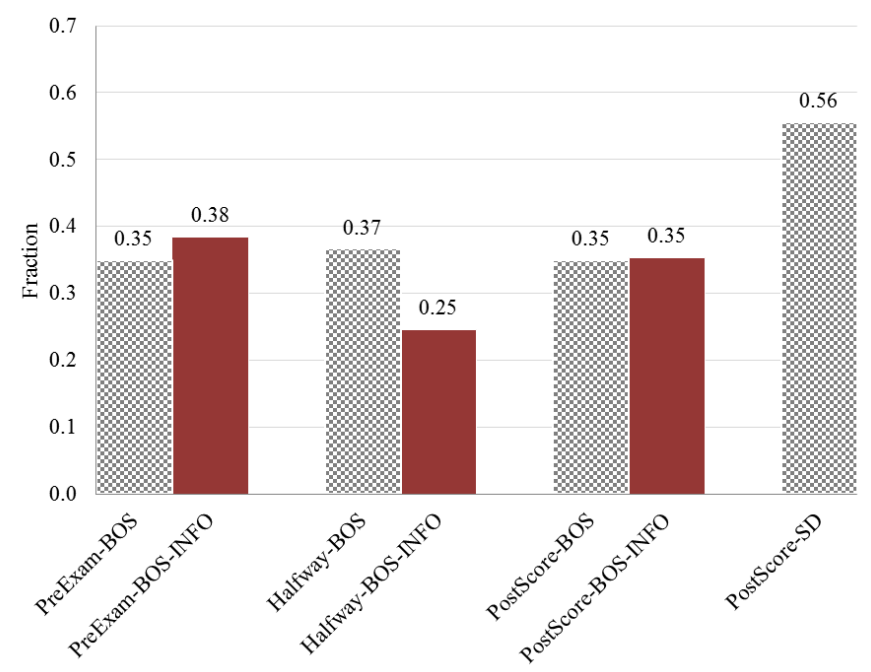

Figure 14: Aptitude-Stably Matched Pairs

Next I compare the three new mechanisms with PostScore-SD. PostScore-SD is the bestperforming mechanism in Section 3.3, and as previously mentioned, it is natural to assume that its performance is not affected by the change of information environment. Figure 14 shows that PostScore-SD yields a larger proportion of aptitude-stably matched pairs than PreExam-BOSINFO $(p=0.031)$, Halfway-BOS-INFO $(p<0.001)$, and PostScore-BOS-INFO $(p=0.014)$. As for the variable WelfareDistortion (Figure 15), the distribution under PostScore-SD still exhibits a smaller variance compared to PreExam-BOS-INFO $(p=0.008)$ and Halfway-BOSINFO $(p=0.016)$. Moreover, the positive relationship between overconfidence and individual welfare remain unchanged under PreExam-BOS-INFO and Halfway-BOS-INFO (see Figure 16 and Table 6).
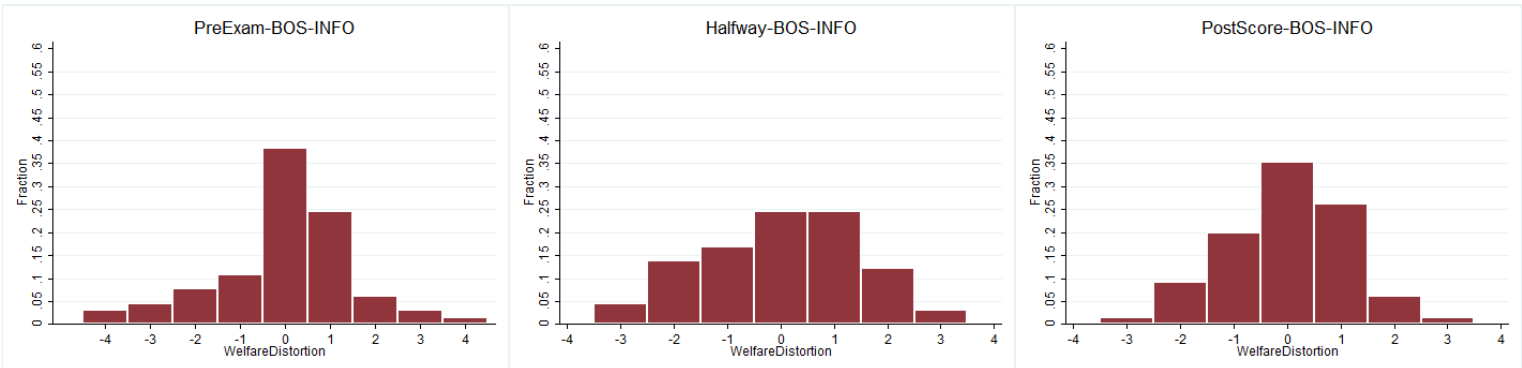

Figure 15: Distributions of Individual Welfare Distortion from Aptitude-Stability 

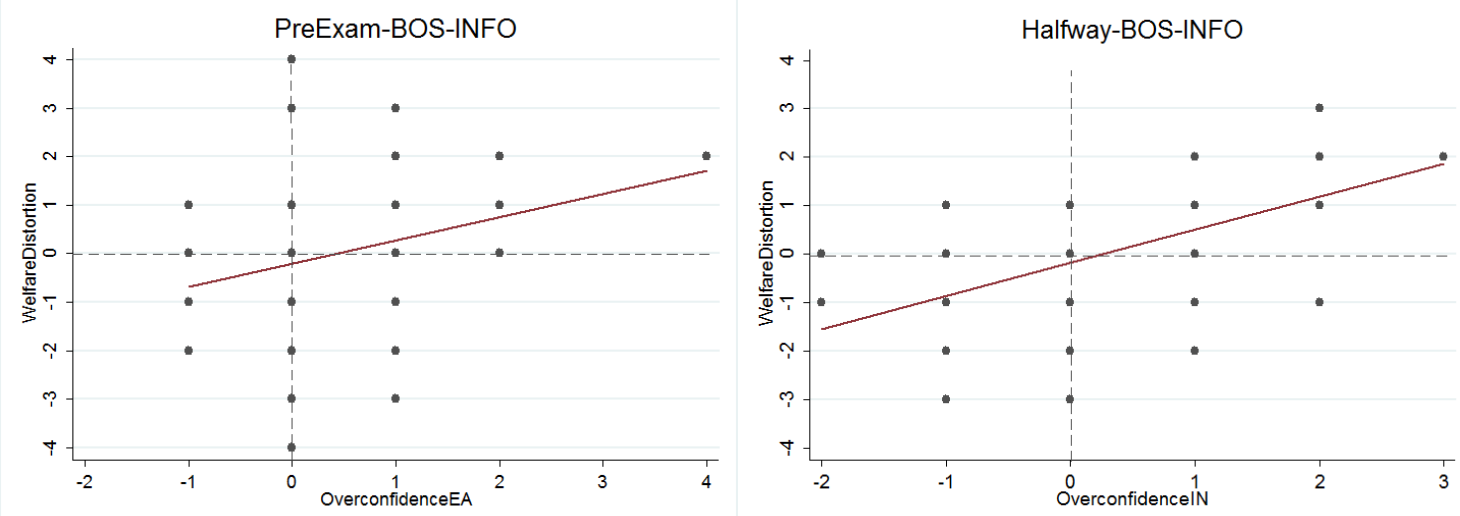

Figure 16: Overconfidence and Individual Welfare Distortion

Table 6: Individual Welfare Distortion (OLS)

\begin{tabular}{r|c|c|c}
\hline Dep. Var. & \multicolumn{3}{|c}{ WelfareDistortion } \\
\hline & $(1)$ & $(2)$ & $(3)$ \\
& PreExam-BOS-INFO & Halfway-BOS-INFO & PostScore-BOS-INFO \\
\hline OverconfidenceEA & $0.495^{* * *}$ & 0.161 & -0.044 \\
& $(0.177)$ & $(0.193)$ & $(0.060)$ \\
OverconfidenceIN & & $0.553^{* *}$ & 0.010 \\
& & $(0.210)$ & $(0.059)$ \\
ExamError & $0.565^{* * *}$ & $0.631^{* * *}$ & $0.989^{* * *}$ \\
& $(0.150)$ & $(0.150)$ & $(0.038)$ \\
GuessedOtherEA & $0.726^{* * *}$ & 0.255 & -0.018 \\
& $(0.189)$ & $(0.215)$ & $(0.054)$ \\
GuessedOtherIN & $0.230^{* *}$ & -0.119 & -0.004 \\
& $(0.102)$ & $(0.110)$ & $(0.033)$ \\
RiskAverse & & 0.037 & -0.009 \\
& 0.037 & $(0.121)$ & $(0.040)$ \\
& $(0.037)$ & 0.017 & -0.002 \\
Female & 0.091 & $(0.035)$ & $(0.010)$ \\
& $(0.319)$ & $0.514^{*}$ & 0.090 \\
Constant & $-0.882^{*}$ & $(0.297)$ & $(0.090)$ \\
& $(0.484)$ & -0.711 & 0.024 \\
Observations & 65 & $(0.436)$ & $(0.138)$ \\
\hline
\end{tabular}

Notes: Standard errors are shown in parentheses. $* * *, * *$, and $*$ indicate significance at the $1 \%, 5 \%$, and $10 \%$ levels, respectively. 


\section{Appendix C: Supplementary Tables and Figures}

Table 7: Standardized Exams in Representative Countries (Year: 2014)

\begin{tabular}{|c|c|c|c|}
\hline Country & Standardized Exam & $\begin{array}{c}\text { Number of } \\
\text { Participants } \\
\text { or Applicants }\end{array}$ & Data Source \\
\hline China & $\begin{array}{c}\text { National College } \\
\text { Entrance Exam } \\
\text { (Gaokao })\end{array}$ & $9,390,000$ & http://gaokao.eol.cn/ \\
\hline Greece & Panhellenic Exams & 104,616 & http://edu.klimaka.gr/ \\
\hline Russia & Unified State Exam & 757,303 & $\begin{array}{c}\text { http://vestnikkavkaza.net/articles/society/ } \\
57810 . \mathrm{html}\end{array}$ \\
\hline $\begin{array}{l}\text { South } \\
\text { Korea }\end{array}$ & $\begin{array}{l}\text { College Scholastic } \\
\text { Ability Test }\end{array}$ & 640,619 & http://www.kice.re.kr/main.do?s=suneung \\
\hline Turkey & $\begin{array}{l}\text { Higher Education } \\
\text { Exam-Undergraduate } \\
\text { Placement Exam }\end{array}$ & $2,086,115$ & http://www.osym.gov.tr/ \\
\hline
\end{tabular}

Notes: The statistic for Greece is from the year 2015.

Table 8: Distribution of Score Rankings (Example 1)

\begin{tabular}{c|c}
\hline Score Ranking $r_{s}$ & Probability \\
\hline$(2,1,3)$ & $26 / 64$ \\
$(2,3,1)$ & $17 / 64$ \\
$(1,2,3)$ & $17 / 64$ \\
$(1,3,2)$ & $1 / 64$ \\
$(3,2,1)$ & $1 / 64$ \\
$(3,1,2)$ & $2 / 64$ \\
\hline
\end{tabular}


Table 9: Descriptive Statistics of Key Variables (Laboratory Experiment)

\begin{tabular}{r|c|c|c|c}
\hline Variable & Mean & Std. Dev. & Min & Max \\
\hline AptitudeRank & 3 & 1.416 & 1 & 5 \\
ExamError & 0 & 1.205 & -3 & 3 \\
OverconfidenceEA & 0.505 & 1.211 & -3 & 4 \\
OverconfidenceIN & 0.257 & 1.192 & -4 & 4 \\
GuessedOtherEA & 0.029 & 1.515 & -4 & 3 \\
GuessedOtherIN & -0.213 & 1.401 & -4 & 3 \\
RiskAverse & 12.305 & 4.232 & 0 & 20 \\
Female & 0.390 & 0.489 & 0 & 1 \\
\hline Observations & \multicolumn{5}{|c}{315} & \\
\hline
\end{tabular}

Table 10: Ordered Logit Marginal Effects for First Choice

\begin{tabular}{r|c|c|c|c}
\hline PreExam-BOS & \multicolumn{5}{|c}{ Marginal Effects for } \\
\hline FirstChoice $=$ & 1 & 2 & 3 & 4 \\
\hline OverconfidenceEA & $0.301^{* * *}$ & 0.190 & $-0.485^{* * *}$ & -0.005 \\
AptitudeRank & $-0.269^{* * *}$ & -0.170 & $0.433^{* * *}$ & 0.005 \\
\hline Halfway-BOS & 1 & 2 & 3 & 4 \\
\hline FirstChoice $=$ & $0.079^{* *}$ & $0.269^{* *}$ & $-0.316^{* * *}$ & -0.033 \\
\hline OverconfidenceEA & $0.215^{* *}$ & $-0.253^{* *}$ & $-0 . .025$ \\
OverconfidenceIN & $0.063^{* *}$ & $-0.434^{* * *}$ & $0.510^{* * *}$ & $0.051^{*}$ \\
\hline AptitudeRank & $-0.127^{* * *}$ & \multicolumn{4}{|c}{} \\
\hline \multicolumn{5}{|c}{ Marginal Effects for } \\
\hline PostScore-BOS & 1 & 2 & 3 & 4 \\
\hline FirstChoice $=$ & Marginal Effects for \\
\hline AptitudeRank & -0.012 & $-0.710^{* * *}$ & $0.656^{* *}$ & 0.066 \\
ExamError & 0.010 & $0.604^{* * *}$ & $-0.558^{* *}$ & -0.056 \\
\hline
\end{tabular}




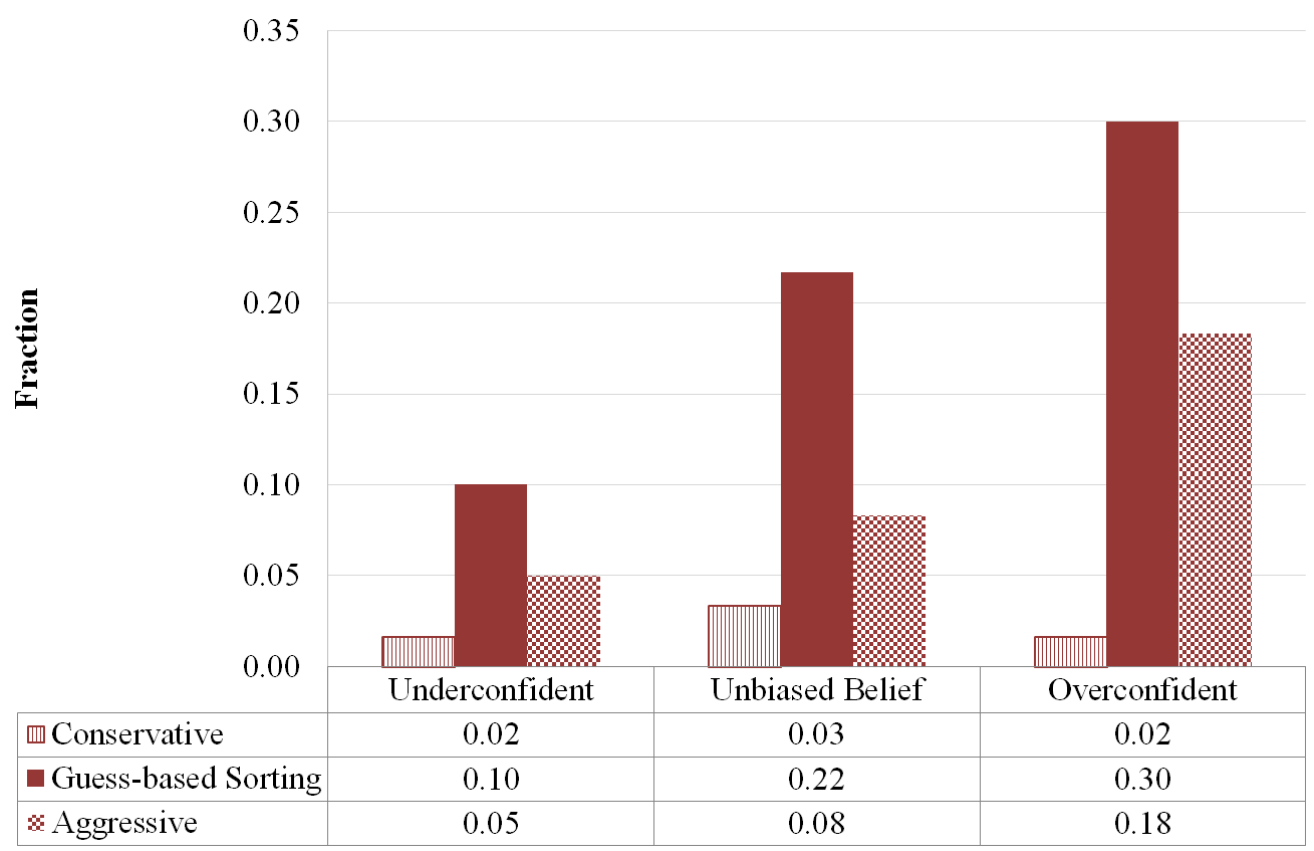

(a) PreExam-BOS

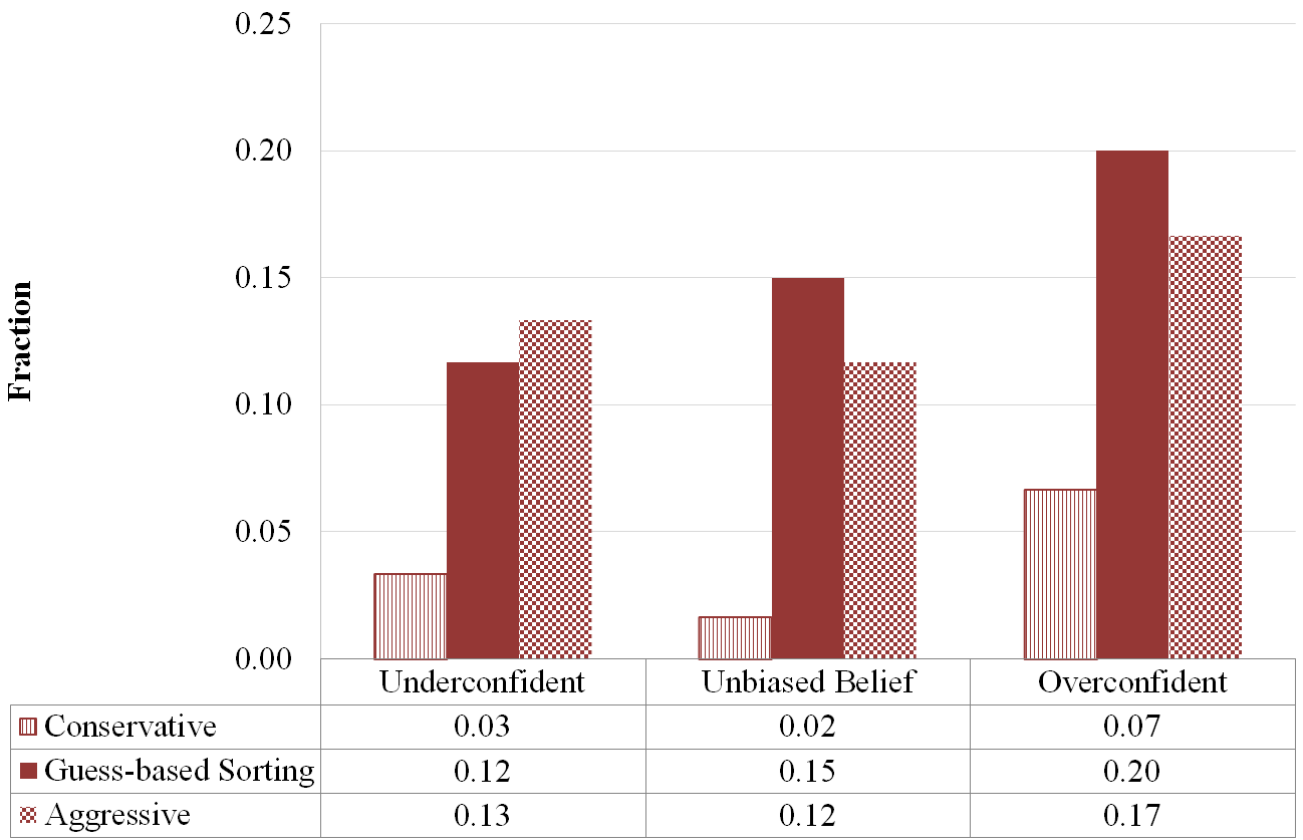

(b) Halfway-BOS

Figure 17: Biased Beliefs and Non-guess-based Sorting Strategies 
Table 11: Individual Welfare Distortion (Ordered Logit)

\begin{tabular}{r|c|c|c}
\hline Dep. Var. & \multicolumn{3}{|c}{ WelfareDistortion } \\
\hline & $(1)$ & $(2)$ & $(3)$ \\
& PreExam-BOS & Halfway-BOS & PostScore-BOS \\
\hline OverconfidenceEA & $0.733^{* * *}$ & -0.628 & -0.150 \\
& $(0.232)$ & $(0.434)$ & $(0.433)$ \\
EverconfidenceIN & & $1.632^{* * *}$ & 0.512 \\
& & $(0.485)$ & $(0.532)$ \\
AggressiveStrategy & $0.571^{* *}$ & $0.547^{* * *}$ & $5.369^{* * *}$ \\
& $(0.238)$ & $(0.209)$ & $(0.925)$ \\
GuessedOtherEA & $1.010^{* * *}$ & $0.851^{* *}$ & -0.280 \\
& $(0.389)$ & $(0.388)$ & $(0.776)$ \\
GuessedOtherIN & 0.251 & 0.261 & -0.079 \\
& $(0.160)$ & $(0.205)$ & $(0.283)$ \\
RiskAverse & & -0.135 & 0.072 \\
& 0.039 & $(0.249)$ & $(0.352)$ \\
Female & $(0.057)$ & $0.118^{* *}$ & $0.142^{* *}$ \\
& 0.053 & $(0.067)$ & $(0.092)$ \\
& $(0.560)$ & -0.623 & -0.045 \\
Observations & 60 & $(0.562)$ & $(0.851)$ \\
\hline
\end{tabular}

Notes: Standard errors are shown in parentheses. $* * *, * *$, and $*$ indicate significance at the $1 \%$, $5 \%$, and $10 \%$ levels, respectively. 
Table 12: Ordered Logit Marginal Effects for Individual Welfare Distortion

\begin{tabular}{|c|c|c|c|c|c|}
\hline (1) PreExam-BOS & \multicolumn{5}{|c|}{ Marginal Effects for } \\
\hline WelfareDistortion $=$ & -2 & -1 & 0 & 1 & 2 \\
\hline OverconfidenceEA & $-0.046^{* *}$ & $-0.062^{* *}$ & -0.030 & $0.109 * * *$ & $0.032^{*}$ \\
\hline ExamError & $-0.036^{*}$ & $-0.048^{*}$ & -0.023 & $0.085^{* *}$ & $0.025^{*}$ \\
\hline AggressiveStrategy & $-0.064^{*}$ & $-0.086^{*}$ & -0.041 & $0.150^{* *}$ & 0.044 \\
\hline (2) Halfway-BOS & \multicolumn{5}{|c|}{ Marginal Effects for } \\
\hline WelfareDistortion $=$ & -2 & -1 & 0 & 1 & 2 \\
\hline OverconfidenceIN & -0.043 & $-0.260 * * *$ & 0.062 & $0.125^{* *}$ & $0.138^{* *}$ \\
\hline ExamError & -0.014 & $-0.087^{* *}$ & 0.021 & $0.042^{* *}$ & $0.046^{* *}$ \\
\hline AggressiveStrategy & -0.022 & $-0.136^{* *}$ & 0.032 & $0.065^{*}$ & $0.072^{*}$ \\
\hline RiskAverse & -0.003 & $-0.019^{*}$ & 0.004 & 0.009 & $0.010^{*}$ \\
\hline
\end{tabular}

\begin{tabular}{r|c|c|c|c|c}
\hline (3) PostScore-BOS & \multicolumn{5}{|c}{ Marginal Effects for } \\
\hline WelfareDistortion $=$ & & -1 & 0 & 1 & \\
\hline ExamError & & $-0.435^{* *}$ & -0.115 & $0.551^{* *}$ & \\
\hline
\end{tabular}

